Article

\title{
Residual Stresses with Time-Independent Cyclic Plasticity in Finite Element Analysis of Welded Joints
}

\author{
Ruben Lostado Lorza ${ }^{1, *}$, Marina Corral Bobadilla ${ }^{1}$, María Ángeles Martínez Calvo ${ }^{1}$ and \\ Pedro María Villanueva Roldán ${ }^{2}$ \\ 1 Department of Mechanical Engineering, University of La Rioja, 26006 Logroño, Spain; \\ marina.corral@unirioja.es (M.C.B.); marian.martinez@unirioja.es (M.Á.M.C.) \\ 2 Rural Engineering Department and Projects, Public University of Navarre, 31006 Pamplona, Spain; \\ pedro.villanueva@unavarra.es \\ * Correspondence: ruben.lostado@unirioja.es; Tel.: +34-941-299527 \\ Academic Editor: Filippo Berto
}

Received: 21 December 2016; Accepted: 6 April 2017; Published: 13 April 2017

\begin{abstract}
Due to the intense concentration of heat in a reduced area when Gas Metal Arc Welding (GMAW) is used to join mechanical components, the regions near the weld bead are subjected to severe thermal cycles. Firstly, the region close to the weld bead that is heated tends to be in compression and, when it cools, tends to be in tension. According to Pilipenko, the material is exposed to elastic compression and, then, reaching the yield limit, undergoes plastic deformation with the appearance of residual stresses followed by elastic-plastic unloading. This could be considered as a strain-stress cycle. This paper applies plastic-strain-range memorization based on time-independent cyclic plasticity theory for butt joints with single V-groove Finite Element (FE) models that were manufactured by GMAW. The theory combines both the isotropic hardening and the nonlinear kinematic hardening rule (Chaboche model) to reproduce the behavior of cyclic plasticity and thus to obtain the residual stresses in welded joint FE models. As a practical example, the proposed theory is validated by three welded joint specimens that were manufactured with different input parameters of speed, voltage, and current. An agreement between the residual stresses obtained by the FE model proposed and those obtained experimentally by the hole drilling method at different depths demonstrates that the proposed theory could be valid for modelling the residual stresses in welded joints when cyclic plasticity is considered over the range of speed, voltage, and current studied.
\end{abstract}

Keywords: finite element analysis; GMAW welded joints; time-independent cyclic plasticity; Chaboche model

\section{Introduction}

Gas metal arc welding (GMAW) is one of the most frequently used processes today for the production of mechanical and structural components. In this process, localized heating, the non-uniform cooling, and the cooling rate accompanied by thermal gradients that arise in the weld zone, generate residual stresses that produce important deformations of welded joints. To a lesser extent, the phase changes at the micro structural level that occur in the weld metal and adjacent Heat Affected Zone (HAZ) also contribute to the residual stress evolution [1,2]. Therefore, it can be confirmed that the residual stresses can be caused by macroscopic or microscopic ways. Thus, for example, macroscopic residual stress may arise due to heating of the material of the weld joint, whereas the microscopic residual stresses can be generated by micro structural transformations [3]. Furthermore, residual stresses are substantially affected by the way in which the welded joints have been manufactured, the welding sequence selected, the material of the base metal and weld cord, the welding process parameters that are considered, and finally the manufacturing process 
selected [4]. Thus, for example, Zambon et al. [5] studied the residual stress distribution in AISI 904L super-austenitic stainless steel sheets manufactured with Laser Beam Welding (LBM). The residual stresses were obtained with X-ray diffraction. The maximum value was obtained in the longitudinal direction of the weld bead and was close to the yield strength of the material. Thibault et al. [6] studied the residual stress on $13 \% \mathrm{Cr}-4 \% \mathrm{Ni}$ plates welded with Metal Inert Gas (MIG) using $410 \mathrm{NiMo}$ as filler metal. The transverse, longitudinal and normal components of the residual stress were measured by neutron diffraction, and the longitudinal stress distribution was also measured by the contour method. Paradowska et al. [7] studied the residual stress distribution for a single bead and for different numbers of beads with the Flux Cored Arc Welding (FCAW) process in low-carbon steel plates. In this case, a neutron diffraction technique was used to investigate the residual stress distribution during the welding process. The residual stress of high-chromium steel AISI 410 used in aircraft engines and heating at different cooling rates was investigated by Olabi [8]. In this case, the hole-drilling method was used to determine the magnitude and distribution of the residual stresses in the welded component before and after the application of post-weld heat treatment. Other authors such as Lostado [9] determined the relationship between the welding parameters of weld cord area, yield stress, tensile strength, residual stresses, hardness and roughness, and the welded joint parameters of speed, current, and voltage in butt joints (X-groove) of EN 235JR manufactured by GMAW using the response surface method (RSM). In this case, the hole-drilling method was used to determine the maximum residual stress in the surface of the welded joint, as close as possible to the foot of the weld bead. In addition, properties such as fatigue, strength, and corrosion resistance in welded components are commonly influenced by residual stresses, and are one of the factors to consider during the design and manufacturing of different products. Thus, Berge [10] used a fracture mechanics theory and an experimental approach to study the effect of plate thickness on the fatigue strength of transverse fillet welds in axial loading. Ferreira [11] used a linear elastic fracture mechanics (LEFM) model to predict the fatigue life of the $\mathrm{T}$ joint, and the influence of the radius of curvature at the weld toe in the fatigue strength of transverse non-load-carrying fillet welded joints loaded in bending and in tension.

More recently, other authors have used the Finite Element Method (FEM) to study the residual stresses and the fatigue in welded joints instead of developing only an experimental study. In this regard, Teng [12] studied with FEM the effects of the butt weld geometry parameters (such as weld toe radius, weld bead flank angle, preparation angle, and plate thickness), and residual stresses on the fatigue crack initiation life of butt-welded joints. Some authors, such as Citarella et al. $[13,14]$ and Carlone et al. [15] studied and modelled with FEM the crack growth in Friction Stir Welded butt joints, which revealed residual stresses induced during the Friction Stir Welding (FSW) process. Other authors have used FEM to reduce costs during the design phase of the welded joints. Lostado et al. [16] used a combination of FEM, Regression Trees, and Genetic Algorithms (GA) to design and optimize complex welded joints that were manufactured by GMAW. In this case, one of the major difficulties that the authors of this work faced was to obtain a good Finite Element (FE) model that had realistic elastic-plastic thermo-mechanical behavior of the complex welded joints that were studied. In addition, this work did not consider the cyclic plasticity and the appearance of the residual stresses in the region near the weld bead during the heating and cooling cycles. However, time-independent cyclic plasticity considering the isotropic hardening and nonlinear kinematic hardening rule (Chaboche model [17]) has been used by several authors to model processes by FEM that undergo cyclic plastic deformation. For example, Lostado [18] used a combination of FEM and GA to determine the most appropriate material behavior model (Time-independent cyclic plasticity considering isotropic hardening and nonlinear kinematic hardening rule (Chaboche model [17])) for use in numerical simulation software and the optimum parameters that define that rule. Mandal [19] proposed a three-dimensional FE of insulated rail joints under wheel-rail contact pressure loading that examining the ratchetting failures of the railhead. The FE model that is proposed is a nonlinear isotropic-kinematic elastic-plastic material model and predicts stress/strain levels in the localized railhead zone that is adjacent to the end post. Chatti [20] applied anisotropic elasto-plasticity behavior considering finite strain analysis with the 
nonlinear isotropic-kinematic hardening model in several sheet-forming processes. These processes included mechanical contact, anisotropic plasticity, and elastic modulus variation with plastic strain and spring back effects.

The current paper applies the plastic-strain-range memorization based on time-independent cyclic plasticity theory for butt joints with single V-groove FE models that were manufactured by GMAW. The theory combines both the isotropic hardening and the nonlinear kinematic hardening rule (Chaboche model) to reproduce the behavior of cyclic plasticity in welded bead by the heating and cooling cycles in those regions close to the weld bead and thus to obtain the residual stresses in welded joint FE models. In the welding process, and according to Pilipenko [21], the material is exposed to elastic compression. When it reaches the yield limit, the material undergoes plastic deformation with the appearance of residual stresses followed by elastic-plastic unloading. This could be considered to be a strain-stress cycle. The FE models proposed to validate the theory were formulated with rate independent plasticity behavior. In addition, because of the low carbon content of the base material (EN 235JR) and the weld bead (wire ER70S-6), as well as the slow cooling to which all welded specimens were subjected in this study, no proposed FE model considered the effects of phase transformation in the local variation of plastic strains. The proposed FE models considered only that the generation of the residual stresses was influenced only by the coupling between heat transfer and thermo-mechanical stress. As a practical example, the proposed theory is validated by three welded joint specimens that were manufactured with different input parameters of speed, voltage, and current (Specimen 01 had a speed of $6 \mathrm{~mm} / \mathrm{s}$ at 26 volts and 140 amps, Specimen 02 had a speed of $6 \mathrm{~mm} / \mathrm{s}$ at 28 volts and $210 \mathrm{amps}$ and Specimen 03 had a speed of $6 \mathrm{~mm} / \mathrm{s}$ at 35 volts and 260 amps). An agreement between the residual stresses obtained by the FE model proposed and those obtained experimentally by the hole drilling method at different depths demonstrates that the proposed theory could be valid for modelling the residual stresses in welded joints when the cyclic plasticity is considered for the range of speeds, voltages, and currents studied.

\section{Generation of Residual Stresses in Welded Joints}

The mechanical behavior and generation of the residual stresses in welded joints are influenced by the combination of heat transfer, microstructure evolution, and the thermo-mechanical stress. Although the effects of microstructure and thermo-mechanical stress on heat transfer are not great, the effects of temperature on microstructure and thermo-mechanical stress are quite important. In addition, the coupling between microstructure and thermo-mechanical stress can be strong [22]. Therefore, it can be confirmed that the greatest generator of residual stresses is thermo-mechanical stress that is caused by the thermal field itself. In this regard, most thermo-mechanical stress analyses have used thermo-elastic-plastic constitutive FE models with rate independent plasticity. Rate-independent plasticity implies that both the viscosity and the relaxation time of the material are zero. This means that the stress gives way instantly to the yield stress and has never missed a (relaxation) time. The analysis of residual stresses and distortion in welded joints usually considers both the rate dependent plasticity and the rate independent plasticity, as they depend mainly on the temperature that the weld joint reaches. Stress relaxation by creep or visco-plasticity is considered to be rate-dependent plasticity. It usually occurs at temperatures greater than one half of the melting point of welded joints (for steels ranges from $600-800{ }^{\circ} \mathrm{C}$ to $1100-1200{ }^{\circ} \mathrm{C}$ ) and in multi-pass welds [2].

In contrast, rate-independent plasticity is independent of the deformation rate and, therefore, of time. However, the high temperature range (temperatures above half of the melting point) is usually considered to be of minor importance in generating residual stress due to the low yield stress at this temperature. Also, during the phase transformation of the welded joint, the volume change induces a local variation in the thermo-mechanical stress behavior. For example, during the transformation from austenite to martensite, the change in volume of the microstructure could put martensite grains into compression and some of the surrounding austenite grains into tension. This phase transformation could cause plastic strain if the yield stress is reached, which will cease when 
the phase transformation has been completed. The geometric changes of the welded joints that are due mainly to the thermo-mechanical stress evolution at high temperatures occur in regions that are cooled from high temperatures. These geometric changes can contribute to the appearance of residual stresses, as shown in Figure 1a.

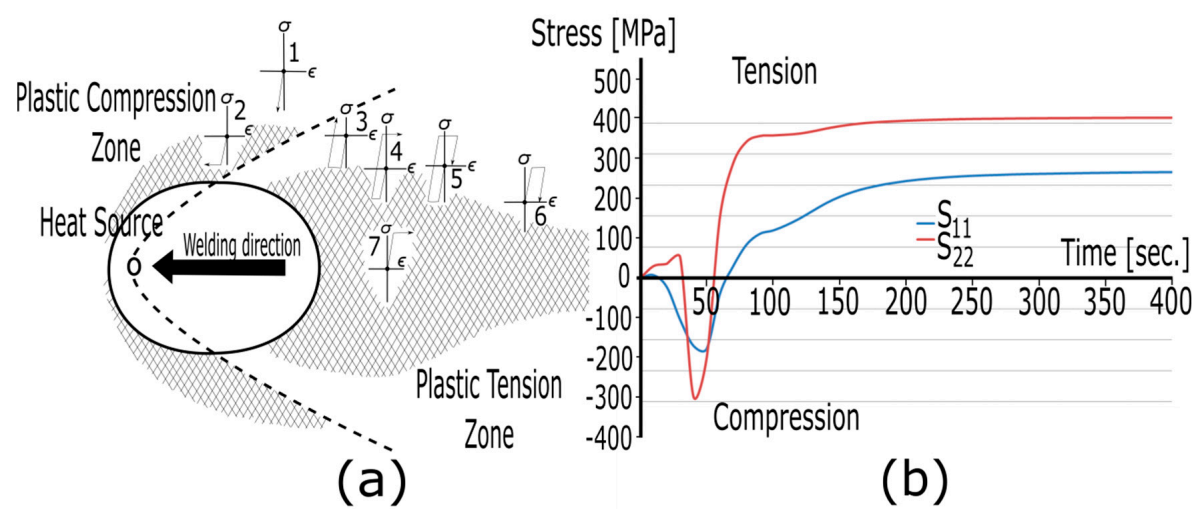

Figure 1. (a) Plastic compression and tension zones that appear in the welding process: Local stress-strain cycles in quasi-stationary temperature field that consider the movement of the heat source [2]; (b) Evolution of the longitudinal and transverse stresses obtained from the proposed finite element (FE) models.

In this figure, the scheme of plastic zone distribution is that of the process of manufacturing a welded joint when the heat source is moving in a line. The heated region tends to be in compression and the cooled region tends to be in tension. The evolution of the strain-stress cycle is represented by points 1 to 7 , which lie at some distance from the weld centerline, without considering temperature dependence. According to Pilipenko [21], point 1 is exposed to elastic compression and, when it reaches the yield limit, the material undergoes plastic deformation (point 2). This is followed by elastic unloading deformation (point 3). Point 7 (a point belonging to the plastic tension zone) is subjected only to plastic tensioning. The temperature of the metal in welded joints varies from the melting point to room temperature and, therefore, undergoes a complete load cycle. In addition, Figure $1 \mathrm{~b}$ shows the variation of the longitudinal and transverse residual stresses that arise in the FE model that is proposed in this paper at a point near the weld toe during the welding of the butt joint with a single V-groove. This figure shows that both stresses occur initially for a moment, which is equivalent to a load cycle. In the current paper, because the temperature reached by the welded joint during the welding process is not substantially greater than the average melting temperature, all proposed FE models were formulated with rate independent plasticity behavior. For the same reason, no proposed FE model considered the effects of phase transformation in the local variations of plastic strains. These last considerations are fully described in Section 6.

\section{Time-Independent Cyclic Plasticity: The Chaboche Model}

Under cyclic loading, the materials show complex mechanical responses that are involved both as elastic and plastic deformations. In this sense, several constitutive elastic-plastic models have been used in the past to describe this cyclic and inelastic behavior of the materials. The main differences in the elastic-plastic behaviors of the models involve the hardening rules and the movement of yield surface.

One of the first models in which the cyclic hardening of the materials was considered was proposed by Armstrong and Frederick [23]. In this case, a kinematic hardening rule was proposed that considered the back-stress evolution by a combination of direct hardening and dynamic recovery terms. In the 1970s, Peterson and Popov [24] proposed the bounding surface model that, considering the modification of the hardening modulus, could follow the entire cyclic process. Based on the above, two model families were developed. They were multi-surface models [25] and two-surface 
models [26]. In the multi-surface models, the hardening phenomenon is controlled between two extreme stages of material behavior-a virgin (or initial) stage and a saturated (or fully-developed) stage. In contrast, the actual and limit surfaces are well defined in the two-surface models, and the movement of the actual surface is controlled by a hardening function. Many real materials usually involve cyclic hardening or softening behavior. This generally depends on the number of cycles and the strain amplitude. In different experimental studies, it has been observed that some alloy steels present a significant strain range-dependent cyclic hardening under strain-controlled cyclic loading. Accordingly, Chaboche et al. [27] proposed a model that considers the strain amplitude dependence of cyclic hardening to describe the cyclic hardening behavior of SS316 stainless steel under varied strain amplitude. Then, Ohno et al. [28] improved this model by introducing a cyclic non-hardening region, within which there is no cyclic hardening, to describe the dependence of cyclic hardening on strain amplitude. A little later, Chaboche [29] and Dafalias et al. [30] considered some significant modifications to kinematic hardening by proposing the time-independent plasticity theories in the range of cyclic loading. The Chaboche model consists of two surfaces for describing cyclic metal material behavior. It is based on the previous model that Frederick-Armstrong [23] proposed. The Chaboche model combines the isotropic hardening rule, to describe cyclic hardening or softening, and nonlinear kinematic hardening to capture the proper characteristic of cyclic plasticity, such as Bauschinger, ratchetting, and mean-stress relaxation effect. The influence of the plastic strain range on the stabilized cyclic response is considered in this model by introducing the plastic-strain-range memorization variable. According to Von Mises theory, the yield function is defined as follows:

$$
f=\bar{\sigma}-(R+k)
$$

where

$$
\bar{\sigma}=\left(\frac{3 \cdot S_{i j} S_{i j}}{2}\right)^{1 / 2} S_{i j}=\sigma_{i j}^{\prime}-\frac{1}{3} \delta_{i j} \cdot \sigma_{k k}^{\prime} \text { and } \sigma_{i j}^{\prime}=\sigma_{i j}-X_{i j}
$$

In this case, $X_{i j}$ is the back-stress tensor that represents the center of the yield surface in the stress space. This isotropic hardening/softening model determines the size of the elastic region during the plastic loading, and is controlled by parameters $R$ and $k$. The initial condition of cyclic hardening is given when $k=\sigma_{\mathrm{y}}$ and $R=0$, whereas the cyclic softening is initially described when the following conditions are fulfilled: $k=\sigma_{\mathrm{y}}-R_{0}$ and $R=R_{0}$. Therefore, the evolution of the variable $R$ could be described as follows:

$$
\dot{R}=b \cdot\left(R_{\infty}-R\right) \cdot \dot{\lambda}
$$

where $b$ and $R_{\infty}$ are the material constants. $R_{\infty}$ represents the limit of the isotropic hardening/softening. If the material undergoes hardening,

$$
\dot{R}=R_{\infty} \cdot\left(1-\mathrm{e}^{-b \cdot \varepsilon_{\text {plastic }}}\right) \cdot \dot{\lambda}
$$

The nonlinear kinematic hardening is derived from the linear-Ziegler rule by adding the term that considers the evolution of the back-stress tensor below:

$$
\dot{\mathrm{X}}=\left[\frac{C}{R+k} \cdot\left(\sigma_{i j}-X_{i j}\right)-\gamma \cdot X_{i j}\right] \cdot \dot{\lambda}
$$

where $C$ and $\gamma$ are the two material constants. When $\gamma=0$, the behavior of the material is considered with a linear-kinematic rule. Several experiments have shown that the asymptotic stress value of cyclic hardening can depend on the prior history. Also, the influence of plastic-strain range on the stabilized cyclic response is evident in the comparison of the different histories of loading used to obtain the cyclic curve. In this sense, a new internal variable that memorizes the prior maximum 
plastic range is introduced to describe a "memory" surface in the plastic strain space. This variable is defined as follows.

$$
F=\frac{2}{3} \cdot \varepsilon_{\text {plastic }} \cdot\left(\varepsilon_{\text {plastic }}-\xi\right)-\rho \cdot
$$

where $\rho$ and $\xi$ are the radius and the center of this non-hardening surface. The change in the memory state takes place only if $F=0$ and when:

$$
\left(\partial F / \partial \varepsilon_{\text {plastic }}\right): \mathrm{d} \varepsilon^{\text {plastic }}>0
$$

Also, the evolutions of the state variables are as follows:

$$
\begin{gathered}
\dot{\rho}=\eta \cdot \mathrm{H}(\mathrm{F}) \cdot n_{j} n_{j}^{*} \cdot \dot{\lambda} \\
\dot{\xi}=\sqrt{\frac{2}{3}} \cdot(1-\eta) \cdot \mathrm{H}(\mathrm{F}) \cdot n_{j} n_{j}^{*} \cdot n_{j}^{*} \cdot \dot{\lambda}
\end{gathered}
$$

In this case, $n$ and $n^{*}$ are the normal vectors to the yield surface $f=0$ and to the memory surface $F=0$ and are defined as follows:

$$
n_{j}=\sqrt{\frac{2}{3}} \cdot \frac{\varepsilon_{\text {plastic }}}{\dot{\lambda}} \text { and } n_{j}^{*}=\sqrt{\frac{2}{3}} \cdot \frac{\varepsilon_{\text {plastic }-\xi}}{\rho}
$$

The coefficient $\eta$ is introduced to induce progressive memory behavior. If $\eta=0.5$, the memorization is instantaneous and stabilization occurs after one cycle. Progressive memory behavior is given by $\eta<0.5$. The dependency of cyclic plastic flow on the plastic strain range is introduced by considering an asymptotic isotropic state, which is defined as follows:

$$
R_{\infty}=Q_{M}+\left(Q_{0}-Q_{M}\right) \cdot \mathrm{e}^{-2 \cdot \eta \cdot \mu}
$$

where $Q_{\mathrm{M}}, Q_{0}, \eta$, and $\mu$ are the material constants in memorization of the plastic strain. In the current paper, the proposed FE models consider the nonlinear-isotropic kinematic hardening rule to describe the cyclic hardening or softening of the welded joints that were subject to local variation in thermo-mechanical stress behavior during its GMAW process.

\section{Manufacturing Procedure and Welding Configuration}

In this paper, three butt joints with a single V-groove of EN 235JR low carbon steel were manufactured with different configuration parameters of the GMAW process. It is well known that the configuration of the GMAW process has a considerable number of input parameters that should be controlled directly by the welding machine (current, voltage, speed, wire diameter, flow rate of the shielding gas, electrode orientation, nozzle-to-plate distance, etc.) [31-33]. These parameters can directly affect the welded joint by changing the yield stress, tensile strength, residual stress, angular distortion, and geometry of the weld bead. In this study, the three specimens that were welded were manufactured automatically by an ABB 1500 IRB robot that was incorporated in an ESAB 180 welding machine (ESAB, London, UK). The speed $(S)$, current $(C)$, and voltage $(V)$ were considered as input parameters to study. The remaining input parameters were treated as constants. Also, the distributed Heat Flux $[\mathrm{KJ} / \mathrm{mm}]$ was given by Equation (12):

$$
Q=\text { Heat Flux }=\frac{V \cdot C \cdot \eta}{S}
$$

where $\eta$ is the weld efficiency (\%), which is considered to be $70 \%$ in the GMAW process [34].

Table 1 shows the values of speed, current, voltage, and power that were considered in this case for the three specimens that were studied. Also, the table includes the heights and widths of each of the three specimens that were studied. 
Table 1. Values of current, speed, voltage, and power for the manufacture of the three welded specimens. Weld bead dimensions (height and width) of the welded specimens.

\begin{tabular}{cccc}
\hline Inputs & Specimen 01 & Specimen 02 & Specimen 03 \\
\hline Current (amps) & 140.0 & 210.0 & 260.0 \\
Voltage (volts) & 26.0 & 28.0 & 35.0 \\
Speed (mm/s) & 6.0 & 6.0 & 6.0 \\
Heat Flux (KJ/mm) & 0.424 & 0.686 & 1.061 \\
Weld bead dimensions & & & \\
Height (mm) & 1.3 & 1.5 & 2.5 \\
Width (mm) & 9.5 & 8.7 & 12.0 \\
\hline
\end{tabular}

The parameters that were considered to be constants and their corresponding values were a flow rate of $20.0 \mathrm{~L} / \mathrm{min}$ for the shielding gas and a distance between the nozzle and plate of $4.0 \mathrm{~mm}$. The electrode consisted of a wire of $1.2 \mathrm{~mm}$ in diameter with a chemical composition and mechanical behavior that were very similar to those of the base metal (ER70S-6). The orientation of the electrode was $80^{\circ}$. The dimensions of the plates that were used to manufacture all welded joints were $30 \times 50 \times 6 \mathrm{~mm}$. The gas mixture was $80 \%$ argon $(\mathrm{Ar})$ and $20 \%$ carbon dioxide $\left(\mathrm{CO}_{2}\right)$. During the GMAW process, the three specimens studied were supported on a flat refractory surface to which only one plate was attached by a clamp, while the other was free to rotate. Thus, the unique force that produced the angular distortion of the welded parts was only the force of thermal shrinkage. The cooling of the welded joints was accomplished in air at a room temperature of $18{ }^{\circ} \mathrm{C}$. The weld cords of all specimens that were studied were deposited sequentially in the same path sequence and on only one side of the plates to be welded in order to create a butt joint with a single V-groove. It is known that different welding path sequences, if applied to the same specimens, can produce different residual stresses [16]. In this case, the three specimens that were studied were manufactured in the same welding path sequence (same weld cord length and direction of welding) and were attached to the ground at the same point. Figure 2a provides a schematic of how the welding process was developed for the three specimens that were studied.

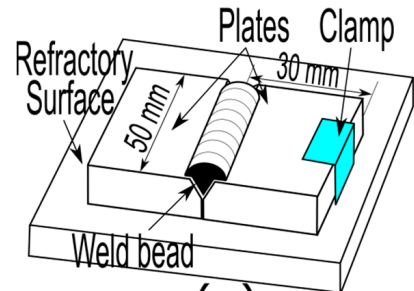

(a)

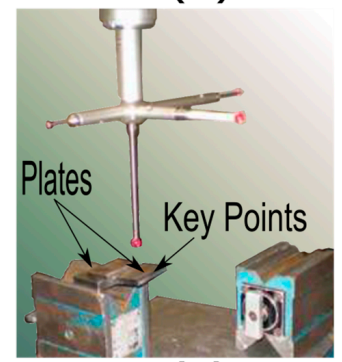

(c)

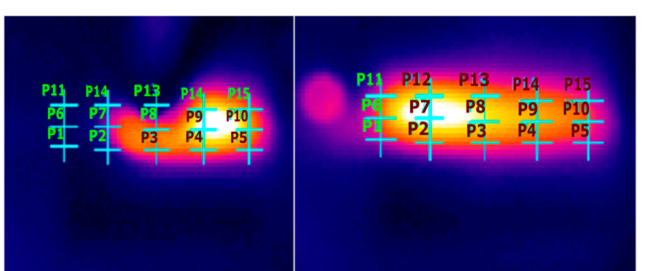

(b)

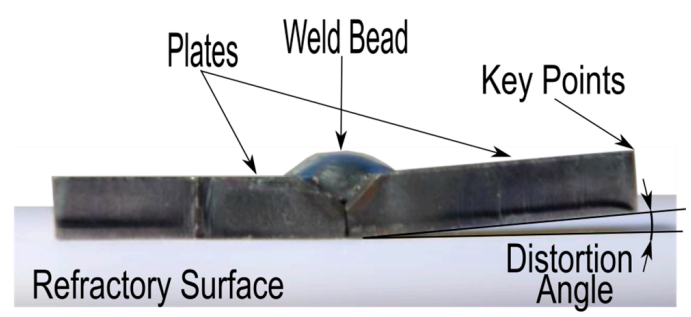

(d)

Figure 2. (a) The welding process used to manufacture the butt joint single V-groove; (b) The temperature recorded with the thermographic camera; (c) The methodology used with the coordinate-measuring machine to obtain the angular distortion; (d) The distortion angle created in the butt joint single V-groove. 


\section{Temperature Field, Angular Distortion, and Residual Stress Measurement}

Obtaining the temperature field during the welding process, the angular distortion and residual stresses can provide important information that can be used to validate any proposed FE model. In the current paper, all of these fields were used to validate the three proposed FE models with a butt joint with single V-groove. The temperature field in the welding process is determined as a function of time for each of the key points of the welded joint. It is usually obtained by direct contact using thermocouples or by indirect contact using Infrared Radiation (IR) technology with a thermographic camera. IR technology has the advantage of providing the temperature field of all the weld parts (plates and weld bead) automatically and accurately. Several researchers have used IR technology successfully to obtain the temperature field in the welding processes [35]. Other researchers have used the results obtained by IR to validate FE models [36,37]. For the current paper, the temperature field was recorded using IR technology during the manufacture of all welded joints. The temperature field was recorded every two seconds during a period of $100 \mathrm{~s}$ (sufficient time for the temperature of the weld to cool significantly) using a thermographic camera (Thermovision 570 AGEMA infrared system AB) (AGEMA Infrared Systems AB, Danderyd, Sweden). To avoid possible errors in the temperature field measurement caused by the transient event in starting and completion of the welding process, only the central points of the cord were considered. Figure $2 \mathrm{~b}$ shows the temperature field obtained experimentally during the experiment at $6 \mathrm{~s}$ and $20 \mathrm{~s}$. In this case, the P1, P5, P6, P10, P11, and P15 locations were not considered for validation of the thermal field of the FE models. Instead, only the P2, P3, P4, P7, P8, P9, P12, P13, and P14 locations were considered.

Angular distortion is the result of irregular expansion and contraction during the heating and cooling cycle of the welding process. It is an indicator of stress to which the welded joint is subjected. This should be avoided as much as possible, since it can affect greatly the final geometry of the welded joint. There are several factors that can cause angular distortion in a welded joint. However, the ones that have been studied most in recent years are the boundary conditions, the input process parameters, and the thermo-mechanical properties of the base material and weld cord. In the current paper, the angular distortions of the three specimens that were studied were measured for a selected group of key points on the edge that suffered most distortion, using a coordinate-measuring machine Zeiss PMC 850 (Zeiss, Oberkochen, Germany). The angular distortions obtained on all specimens were at room temperature. Figure $2 \mathrm{c}, \mathrm{d}$ shows, respectively, the process of measuring the angular distortion on the key points of a welded sample using the coordinate-measuring machine and the distortion angle obtained for a sample of a butt joint with a single V-groove.

Residual stresses are produced mainly by non-uniform heat distribution and plastic deformations during the welding process [38]. Tensile residual stresses are usually induced by shrinkage of the molten region, whereas compression residual stresses are induced by the effect of phase transformations. The maximum values of residual stresses usually appear on the surface of the $\mathrm{HAZ}$ on the toe of the weld cord [3]. In the current paper, the incremental hole drilling non-destructive ASTM E837-13a technique was used [39] to obtain the principal residual stresses in the three specimens. This technique is considered to be a stress-relaxing method that analyzes the stress-relaxation that is produced in a metal part when the material is removed. In this case, six holes were made on both sides of the weld bead (three holes for each of the welded plates) as close as possible to the toe of the weld bead to obtain the residual stresses at eight different normalized hole depths. The eight hole depths that were studied were standardized according to ASTM E837-13a, and the process to obtain them was developed following the procedure described in measurement group TN-503 [40]. These seven normalized holes depths were: $0.127,0.254,0.508,0.762,1.016$, and $1.27 \mathrm{~mm}$. A strain gauge rosette of type CEA-06-062UM-120 was used. It allowed the residual stresses close to the toe of the weld bead to be measured. Each of these rosettes consists of three linear strain gauges by which the longitudinal 
deformations of the three different directions can be obtained. The principal residual stresses from the strains obtained can be calculated by the following equations:

$$
\begin{aligned}
& \sigma_{\mathrm{I}}=\frac{\varepsilon_{1}+\varepsilon_{3}}{4 A}-\frac{1}{4 B} \sqrt{\left(\varepsilon_{3}-\varepsilon_{1}\right)^{2}+\left(\varepsilon_{3}+\varepsilon_{1}-2 \varepsilon_{2}\right)^{2}} \\
& \sigma_{\text {II }}=\frac{\varepsilon_{1}+\varepsilon_{3}}{4 A}+\frac{1}{4 B} \sqrt{\left(\varepsilon_{3}-\varepsilon_{1}\right)^{2}+\left(\varepsilon_{3}+\varepsilon_{1}-2 \varepsilon_{2}\right)^{2}}
\end{aligned}
$$

The coefficients $A$ and $B$ can be calculated by the following equations:

$$
\begin{gathered}
A=\frac{-a(1+u)}{2 E} \\
B=\frac{-b}{2 E}
\end{gathered}
$$

where parameters $a$ and $b$ are the parameters proposed by Schajer [41]. They are the approximations made in attempting to remove the material dependency $A$ and $B$, leaving only the geometric dependency of the residual stress. The calibration coefficients $a$ and $b$ were used to transform the incremental hole-drilling strain data into stress data using blind hole analysis [39,40]. The values of $E$ and $\mu$ correspond to the elastic modulus and Poisson's modulus, which in this case are $E=2,100,000 \mathrm{MPa}$ and $\mu=0.3$ respectively.

In addition, $\alpha$ is the angle from the closest principal axis to the strain gauge no1 and is calculated according to:

$$
\tan 2 \alpha=\frac{\varepsilon_{1}-2 \cdot \varepsilon_{2}+\varepsilon_{3}}{\varepsilon_{1}-\varepsilon_{3}}
$$

If the value of $\alpha$ of each of the normalized depths studied remains constant, the variations of the principal residual stresses for these depths could be considered to be homogeneous $[39,40]$. This procedure was used to obtain the principal stresses $\sigma_{\mathrm{I}}$ and $\sigma_{\mathrm{II}}$ from each of the eight holes' depths corresponding to the six holes studied. Figure 3a shows the milling guide machine (model RS-200, Vishay Measurements Group, Raleigh, NC, USA) with an ultra-high speed air turbine that includes a carbide cutter to drill a hole in the center of the CEA-06-062UM-120 strain gauge rosette. Figure 3b shows the strain gauge rosettes that are glued into the first studied specimen that contain a center hole to relax the material that is adjacent to the weld bead toe. Figure $3 \mathrm{c}$ shows the detail of a profile section in which a hole has been created to measure the residual stress at different depths.

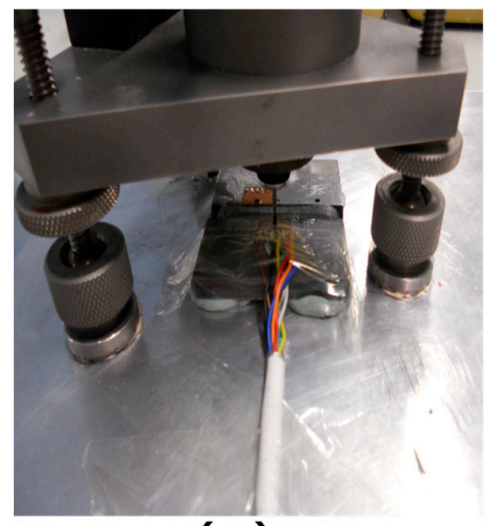

(a)

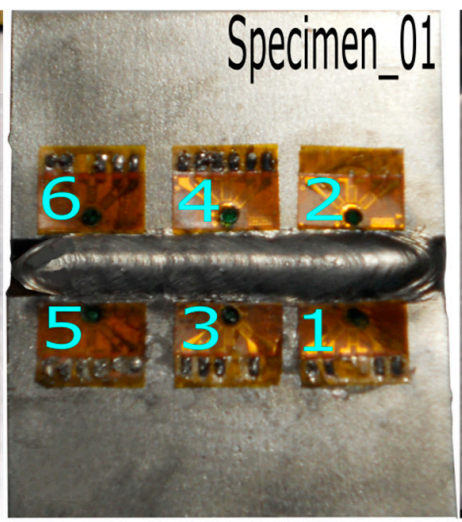

(b)

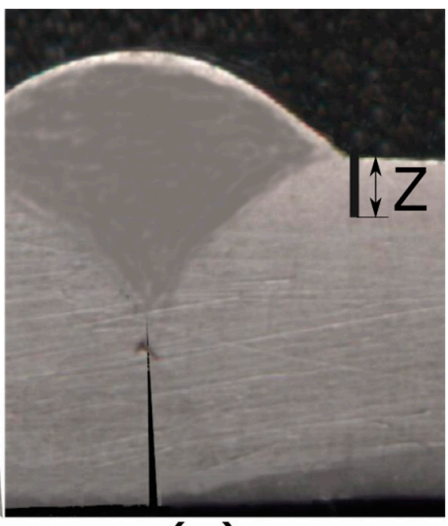

(c)

Figure 3. (a) RS-200 milling guide machine used to measure residual stress; (b) Details of the strain gauge rosette type CEA-06-062UM-120 that is glued to measure the residual stress in the first specimen studied; (c) Details of a profile section in which a hole has been made to measure the residual stress at different depths. 
In order to detect any phase transformation in the weld joint and to identify any hard transformation zones in the weld bead, HAZ, and plates, a metallographic analysis was conducted. This was followed by the measurement of hardness. First, the three welded joints studied were cut into pieces and ground. Then, the faces of the cuts were treated with picric acid so that different areas of the joint would be visible in accordance with ASTM E407 [42]. After the specimens were treated, the faces of the cuts were examined and the images that were obtained by a ZEISS microscope (Zeiss, Oberkochen, Germany) using a magnification of $40 \times$ were digitalized to identify the transformation zones. Figure $4 \mathrm{a}$ shows the digitized image of the 1st specimen studied. It can be seen in Figure $4 \mathrm{~b}$ that the weld cord is formed mainly by ferrite and perlite, although the amount of perlite shown for the base metal is greater than that shown for the weld cord (Figure 4c) and, therefore, no significant changes of phase were detected. Also, the HAZ for all specimens studied (Figure 4d) has a much smaller area than that of the weld cord itself. This may be due to the low carbon content of both base material (EN 235JR) and weld bead (Wire ER70S-6) that were used in this case and the slow cooling of all welded specimens.

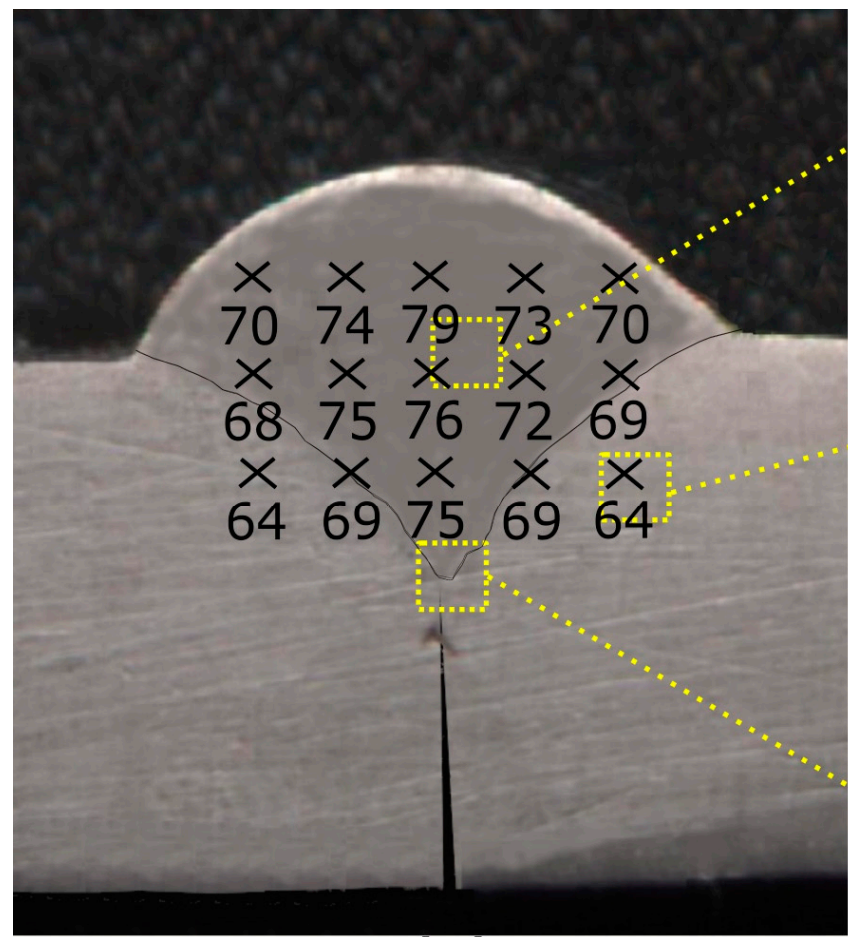

(a)
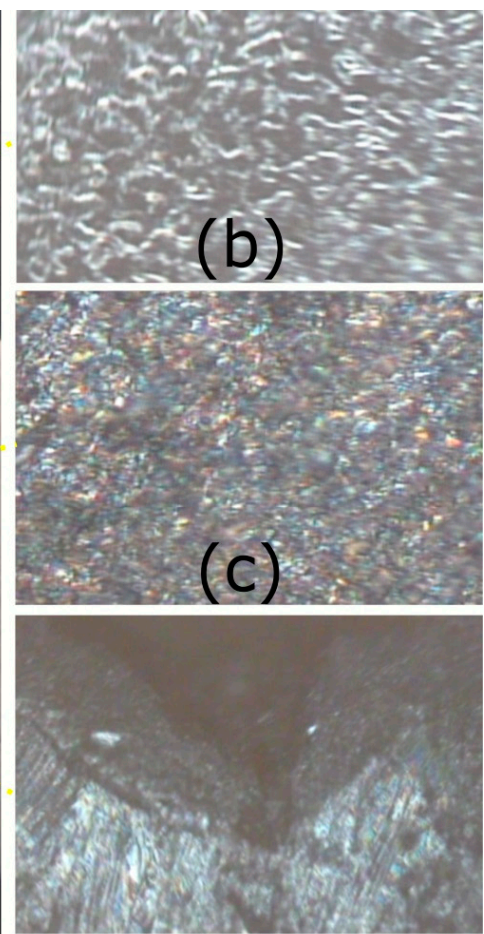

(d)

Figure 4. (a) Image obtained by the microscope showing the different phase changes in the welded joint; (b) Ferrite and perlite in the weld cord; (c) Ferrite and perlite in the base metal cord; (d) Reduced area of the HAZ.

In addition, a Hoyton Rockwell type 1003A durometer (Hoyton, Leioa, Spain) was used to obtain the values of hardness from various points of the three welded joints that were studied (weld bead, base metal and HAZ) according to ASTM E92 [43]. In this case, the value of the applied force was $60 \mathrm{kp}$ using a diamond cone in a the HRA scale. Figure 4a shows the value of hardness HV at different points on the weld cord, the base metal, and the HAZ obtained for the first specimen respectively. This figure shows that the point of maximum hardness has a value of 79 HRA, whereas the point of minimum hardness has a value of $64 \mathrm{HRA}$. This means that no significant changes of phase were detected or important hard transformation zones found [44]. Similar results were obtained for the other two specimens analyzed. According to the metallographic analysis and the measurement of hardness developed, 
the FE models that are proposed in the current paper did not take into account the microstructure evolution and phase transformation. These FE models considered only that the generation of the residual stresses was influenced only by the heat transfer and thermo-mechanical stress.

\section{FE Model Proposed}

As a general rule, welded joints based on FE models almost always consider the elastic-plastic behavior, as well as the phenomena of heat transfer of conduction, convection, and radiation. This enables the distribution of temperature, residual stresses, and distortions to be determined accurately. One of the first studies in which the FE method was used to calculate temperatures, stresses, and distortions during the welding process was conducted by Friedman [45]. A short time later, Muraki et al. [46] developed an elastic-plastic FE computer program for calculation of the welding thermal stresses and metal movement during the welding process. Karlsson [47] and, subsequently, Karlsson et al. [48] analyzed the temperature field and the thermal stresses in single-pass butt welding of carbon-manganese pipe using the ADINAT and ADINA FE codes. Pardo [49] developed an FE model of the temperature field and the angular distortions in welded joints. In this case, the modeling of the thermal field in the three-dimensional FE model was developed by applying heat flux assuming a Gaussian distribution. The FE model considered the temperature-dependent material properties in order to better predict the deformations and the angular distortions of the weld. More recently, the distortion angle and the temperature field of single pass Metal Inert Gas (MIG) welding were modeled with WeldSimS numerical FEM code [50]. In this study, the proposed FE models considered coupled thermal-mechanical fields, including the phenomena of radiation, conduction, and convection with temperature-dependent material behavior. The heat from the moving welding arc was modeled assuming a double ellipsoidal distribution [51]. Attarha [52] studied welding temperature distribution using FEM in the HAZ for similar and dissimilar butt welded joints that were manufactured by the Gas Tungsten Arc Welding (GTAW) process. In this work, the FE model included the phenomena of radiation, conduction, convection, and a double ellipsoidal distribution for the input heat flux. The FE model was validated experimentally by thermocouples.

Other studies of welding processes with FEM focused primarily on the distortion of the welded joints, instead of the temperature fields. For instance, Bachorski et al. [53] used the volume shrinkage approach that was obtained from FE models to predict the distortion in the GMAW process. Zhang et al. [54] proposed FE models considering temperature-dependent material behavior and double ellipsoidal distribution for the investigation of the effects of a selected group of the input parameters on the angular distortion in Tungsten Inert Gas (TIG) welding. The latter were: the nozzle-to-plate distance, current, voltage, and speed.

Finally, other researchers have focused their studies of welding processes with FEM on the residual stresses of welded joints. For example, in 1993, Josefson [55] estimated the residual stresses in a multi-pass weld and in a spot-welded box beam. In this work, the commercial FE codes for non-linear analyses used in this case were SOLVIA and ABAQUS. Murthy et al. [56] analyzed the residual stresses due to welding and quenching processes. In this work, the proposed FE model considered the thermo-elasto-plastic behavior to take into account the non-linearities due to variation of material properties and heat transfer coefficients with temperature. Also, the proposed FE model considered the radiation phenomenon, as well as the phase transformation effects. Brickstad and Josefson [57] obtained the residual stresses from multi-pass butt-welded stainless steel pipes using ABAQUS software. In this case, two dimensional and axisymmetric FE models were developed in order to obtain the thermal distribution and then, the structural field. The residual stresses were obtained in the welded pipe after the latter cooled.

Similarly, Wen and Ferrugia [58] modeled the residual stresses in welded joints of steel pipes using ABAQUS. In this case, the temperature dependency of material properties was taken into account for the weld bead and pipe. Deng and Murakawa [59] developed an uncoupled thermal-mechanical FE model to determine the temperature field and residual stresses in stainless steel pipe that was welded 
by Gas Tungsten Arc Welding (GTAW). In this case, the double ellipsoidal distribution proposed by Goldak [51] was used in modeling the heat from the moving welding arc. The proposed FE model considered both conduction and convection, so that the convention was modeled according to the temperature-dependent heat transfer coefficient [57]. Other authors, including Armentani et al. [60] and Sepe et al. [61], studied the influence of preheating and post-heating treatments on residual stresses in a single-pass butt joint welded by GMAW using 2- and 3-dimensional FE models. In this case, the thermo-mechanical behavior of the welded joint was calculated using a sequentially-coupled formulation that considered the element birth and death technique. The authors found that the residual stresses decrease when the preheating temperature increases.

In the current paper, using MSC Marc software [62], FE models based on butt joints with a single V-groove were developed to determine, in each case, the temperature field, the angular distortion, and the residual stresses. As was mentioned in previous subsections, all FE models proposed in this paper considered rate-independent plasticity behavior and did not consider the effects of phase transformation in the plastic strains. The next subsection shows the process that was followed to configure the FE models of the proposed butt welded joints.

\subsection{The Proposed Thermal FE Model}

Based on the three specimens that were studied and according to the input parameters and the weld bead dimensions (height and width) that appear in Table 1, three FE models were generated in order to determine the thermal field that is created during the welding process. These models consisted of a weld bead, a pair of plates, and a refractory surface. The thermal FE models considered in their development coupled thermal-mechanical fields and temperature-dependence of the base material (EN 235JR) and the weld bead (wire ER70S-6) (thermal conductivity, thermal expansion coefficient, specific heat, and elastic modulus). All proposed FE simulations used the technique of birth and death of elements to model the addition of weld metal to the parts to weld [53] and considered the phenomena of conduction, convection, and radiation [63]. The shape of the weld beads was modeled by a parabolic function [64]. The size of each weld bead (height and width) for each of the three FE models was obtained from the corresponding manufactured specimen. In a way that was similar to that in the manufacturing process of the specimens (see Section 4), one of the plates was clamped to a refractory surface and the other plate was simply supported on the refractory surface [50]. A total of thirteen parameters were considered for the proposed FE models, which defined the weld flux, as well as the conduction and convection phenomena.

The weld flux for all FE models was assumed to take a double ellipsoidal shape according to Goldak [51], and was formulated with the following equations:

$$
\begin{aligned}
& q_{f}(\mathrm{x}, \mathrm{y}, \mathrm{z})=\frac{6 \sqrt{3} f_{f} Q}{a b c_{f} \pi \sqrt{\pi}} e^{\left(\frac{-3 x^{2}}{a^{2}}\right)} e^{\left(\frac{-3 y^{2}}{b^{2}}\right)} e^{\left(\frac{-3 z^{2}}{c^{2}}\right)} \\
& q_{r}(\mathrm{x}, \mathrm{y}, \mathrm{z})=\frac{6 \sqrt{3} f_{r} Q}{a b c_{f} \pi \sqrt{\pi}} e^{\left(\frac{-3 x^{2}}{a^{2}}\right)} e^{\left(\frac{-3 y^{2}}{b^{2}}\right)} e^{\left(\frac{-3 z^{2}}{c^{2}}\right)}
\end{aligned}
$$

where $q_{f}$ and $q_{r}$ are, respectively, the weld flux rates per unit of volume in the front and rear weld pools respectively; $Q$ is the applied power calculated according to Equation (12); $a$ is the weld width along the tangent direction $X ; b$ is the weld penetration depth along the arc direction $Y ; c_{f}$ and $c_{r}$ are the forward and rear weld pool lengths in the weld path direction $Z ; f_{f}$ and $f_{r}$ are dimensionless factors given by:

$$
\begin{aligned}
& f_{f}=\frac{2}{\left(1+\frac{c_{r}}{c_{f}}\right)} \\
& f_{r}=\frac{2}{\left(1+\frac{c_{f}}{c_{r}}\right)}
\end{aligned}
$$


They are the parameters of the FE model that had to be adjusted for forward length, rear_length, width, and depth. The double ellipsoidal source is shown in Figure 5a.

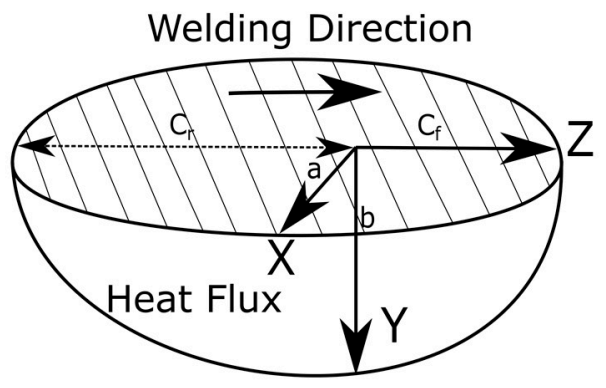

(a)

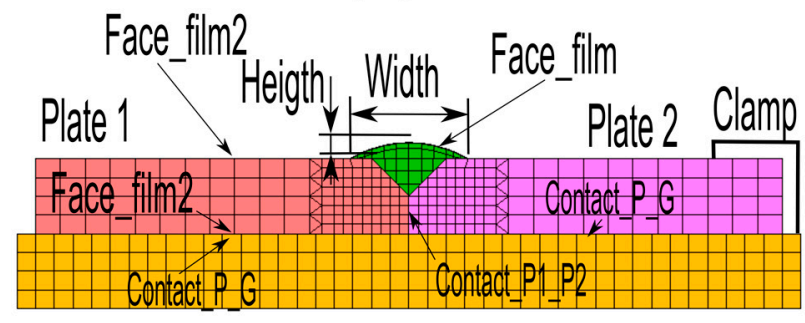

(c)

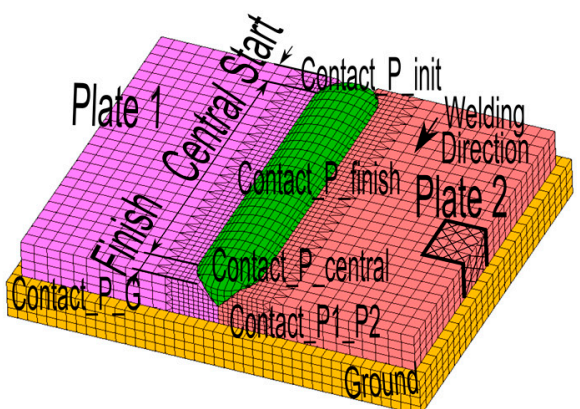

(b)

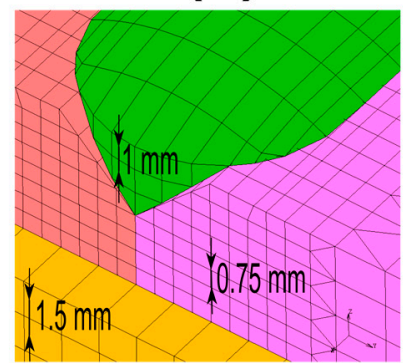

(d)

Figure 5. (a) Double Ellipsoidal Weld Flux showing the local coordinate dimensions; (b) Thermal contacts proposed in the FE model to solve the conduction phenomena; (c) Thermal convection coefficients proposed in the FE model to solve the convection phenomena; (d) Main dimensions of the proposed FE model.

Similarly, the thermal conduction phenomena considered six parameters that were based on the different pairs of contacts that made up the welded joints (melting_point, contac_P_init, contac_P_center, contac_P_end, contact_P1_P2, and contact_P_G). The melting_point parameter corresponds to the melting temperature of the weld bead. Contac_p_init, contac_p_center and contac_p_end are, respectively, the corresponding thermal contacts between the weld bead and both plates for the starting zone of the bead, the central zone of the bead and the end zone of the bead. This difference in the thermal contacts is due mainly to the fact that the size of the weld cord generated in the central zone of the welded joint is greater than those areas of the beginning and ending of the weld cord (see Figures $3 \mathrm{~b}$ and $5 \mathrm{~b}$ ). On the other hand, the parameter contact_P1_P2 corresponds to the thermal contacts between plate 1 and plate 2, whereas contact_P_G corresponds to the thermal contact between plates 1 and 2 with the ground.

In addition, the phenomenon of thermal convection was modelled using three different film coefficient parameters (face_film, face_film2, and face_film3). Face_film was defined as the coefficient of thermal convection between the weld bead and the air. Face_film 2 corresponded to the coefficient of thermal convection between the sides and the top of the two plates and air. Finally, Face_film3 corresponded to the coefficient of thermal convection between the bottom of the plate that is not clamped to the refractory surface and can rotate (plate 1) and the air (Figure 5c). This last coefficient was defined as able to estimate the heat transfer by convection between the moving plate (plate 1) and the air, although initially this plate was in contact with the rigid surface and not with air. As the simulation progressed, the angular distortion of the welded joint made it possible to circulate the air between the refractory surface and plate 1 and, therefore, thermal convection was possible. Finally, the radiation was taken into consideration in the FE model and applied to the weld bead and the surrounding areas. Also, the three proposed FE models respect scrupulously the dimensions of height 
and width of the specimens that were welded. The minimum mesh size that was considered for the FE models that were generated were $0.75 \mathrm{~mm}$ for the plates, $1.0 \mathrm{~mm}$ for the weld bead, and $1.5 \mathrm{~mm}$ for the refractory surface (Figure $5 d$ ).

The thirteen parameters that are defined by each of the three FE models were adjusted by evolutionary optimization techniques that are based on Genetic Algorithms (GA) [16] using as reference the temperature field obtained by the thermographic camera. Subsequently, these thirteen parameters were set as boundary conditions for the three proposed FE models to solve the angular distortion and residual stress fields.

\subsection{Angular Distortion and Residual Stresses of the Proposed FE Model}

The degree of the finite element shape functions for the displacements in thermo-mechanical problems should be, in general, one order higher than for the thermal analysis. This is because the temperature field becomes the thermal strain field in the mechanical analysis. The strains and their corresponding stresses are obtained as derivatives of the displacement field in the mechanical analysis. In general, linear elements are preferred since smaller low-order elements perform better than larger high-order elements when a nonlinear problem, such as welded joints, is solved [65]. In this regard, Friedman $[45,66]$ used quadratic elements to solve welded joint problems instead of low-order elements or linear elements. However, he was in agreement with Hibbit and Marcal [67] that a fine mesh with linear elements is preferred since brick or hexahedral elements, in three dimensions, are the recommended elements in solving problems of plasticity [68,69]. On the other hand, Citarella et al. [13,14] and Carlone et al. [15] modelled the residual stresses induced during the Friction Stir Welding (FSW) process in order to study the crack growth. In this work, a thermo-mechanical FEM model with three-dimensional eight-node hexahedral elements (linear elements) with an average element size that was set at $0.5 \mathrm{~mm}$ at the cutting surface was created to predict the process-induced residual stress field. Then, the computed stress field was transferred to a Dual Boundary Element Method (DBEM) environment and superimposed onto the stress field produced by a fatigue traction load that was applied to a notched specimen. The notched specimen was modeled using a combination of reduced quadratic (the node at the element center is missing) and triangular quadratic elements.

In the current paper, and according to what was explained previously, hexahedral elements with linear shape functions with a finer mesh size than that of the previous FE thermal models were used to solve the strain, angular distortion, and residual stress fields. The minimum mesh size that was considered for all FE models generated was $0.18 \mathrm{~mm}$ for the plates, $0.25 \mathrm{~mm}$ for the weld bead, and $1.5 \mathrm{~mm}$ for the refractory surface. These new FE models considered, as fixed input, the thirteen parameters that were adjusted previously in the thermal field to define the weld flux, thermal conduction, and thermal convection phenomenon, as well as the radiation and the gravity field [50,54]. For the type of welded joint studied in this paper, the thermal conduction, thermal convection, and radiation influence notoriously the effect of the thermal shrinkage of the welded joint, as they are able to increase the angular distortion. In contrast, for the type of welded joint studied, the gravity field is opposed to the effect caused by the thermal shrinkage, thereby decreasing the angular distortion (See Figure 2d). Also, the parameters that defined the cyclical behavior of Chaboche of these new FE models (Yield stress $=235 \mathrm{MPa}, b=17.7, C=24,506 \mathrm{MPa}, \gamma=2462.6, Q_{\mathrm{M}}=191.4 \mathrm{MPa}, Q_{0}=221.9 \mathrm{MPa}, \mu=118.3$, $\eta=0.5$ and $n=4.1$ ) were adjusted iteratively. In this case, a Mean Absolute Error (MAE) threshold value of about 15 was preset as an acceptable error and used at an industrial level [16]. The iterative adjustment was continued until the MAE of each of the three studied specimens was about 15. MAE provided a means to determine the accuracy of the proposed FE models when the parameters that configured the cyclical behavior of the Chaboche model were considered (See Equation (22)).

$$
\text { MAE }=\frac{1}{m} \cdot \sum_{k=1}^{m}\left|Y_{\text {kExperiment }}-Y_{\text {KFEmodel }}\right|
$$


In this case, $Y_{\text {kExperiment }}$ are the principal residual stresses $\left(\sigma_{I}\right.$ and $\left.\sigma_{I I}\right)$ that were obtained experimentally at each depth hole. $Y_{\text {kFEModel }}$ are those that were obtained from the proposed FE models and $m$ is the number of depths studied (in this case $m=6$ ). Figure 6a shows the butt joints with a single V-groove FE model that were proposed for determination of the strain, angular distortion, and residual stress fields. The transition zone that was generated to adapt a mesh size of $0.18 \mathrm{~mm}$ to a mesh size of $1.5 \mathrm{~mm}$ in the plates is shown in Figure $6 \mathrm{~b}$.

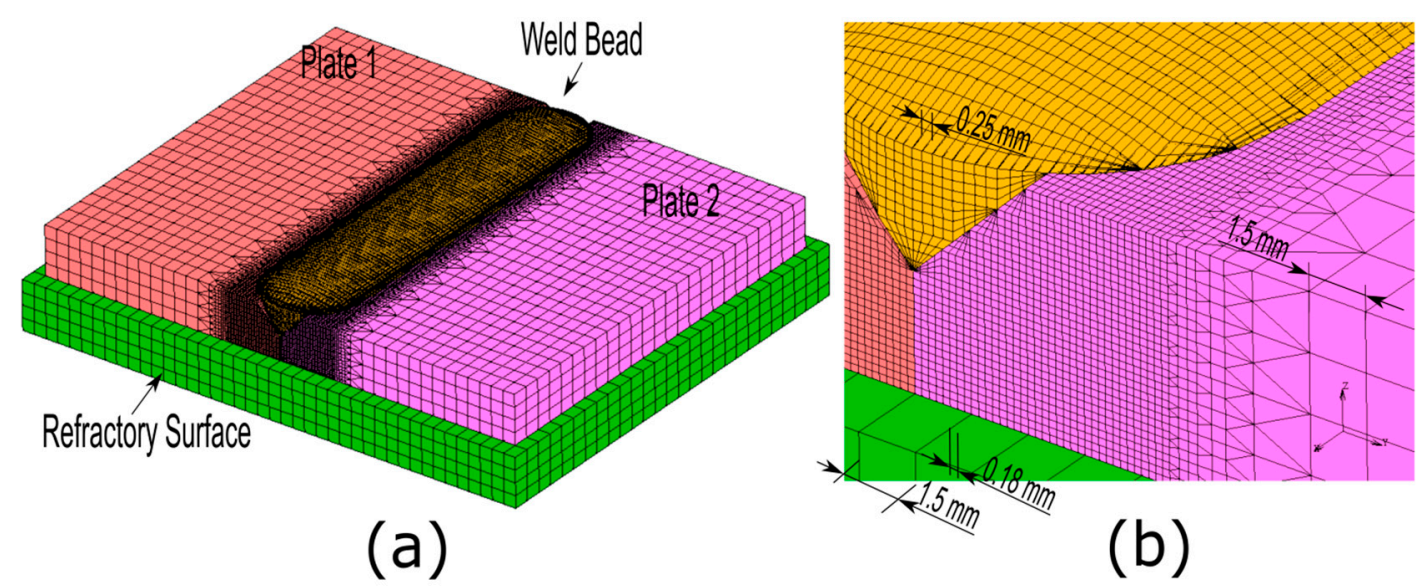

Figure 6. FE model of a butt joint with a single V-groove defined for the first specimen studied.

After the FE models were generated, they were simulated in three servers by an Intel Xeon Processor, CPU 3.4 GHz (8 processors) and 32.00 GB (RAM). The average computational time was approximately $10 \mathrm{~h}$ for each simulated FE model.

\section{Results}

\subsection{Results Obtained from the Thermal Field}

The adjustment process using GA consisted of setting the thirteen parameters that defined each of the three FE models of the proposed single V-groove butt joints. In a similar way to the previous work [5], the objective function $J_{\text {tempj }}$ to be minimized to adjust each of the thirteen parameters was applied to each of the three proposed FE models. It was defined as follows:

$$
J_{\text {tempj }}=\frac{\sum_{i=0}^{n}\left|T_{\mathrm{FEM}(\mathrm{i})}-T_{\mathrm{EXP}(\mathrm{i})}\right|}{\sum_{i=0}^{n}\left|T_{\mathrm{FEM}(\mathrm{i})}-T_{\mathrm{EXP}(\text { average })}\right|}
$$

where $n$ is the estimated time that the welding process takes until the parts have cooled to less than $130{ }^{\circ} \mathrm{C}$ (in this case $\left.100 \mathrm{~s}(n=100)\right) . T_{\mathrm{EXP}(\mathrm{i})}$ is the temperature of each time point ( 0 to $\left.100 \mathrm{~s}\right)$ obtained experimentally and $T_{\mathrm{FEM}(\mathrm{i})}$ is that obtained by FEM. This objective function $J_{\text {tempj }}$ was applied on nine key points $(j=9)$, three of which were located on the welding cord itself, and another six key points that were distributed evenly over the two welded plates. Figure 7 shows an example of the adjustment process for the first specimen studied of a butt joint with single V-groove FE model for the temperature of key node 3, which is located at the base of the weld bead, and for key node 10, which is located on the weld bead itself (See Figure $2 b$ ). Figure 7a,b provides, respectively, a comparison of the temperature of key nodes P3 and P10 obtained experimentally by a thermographic camera and the FE model during a period of $100 \mathrm{~s}$ without adjusting the parameters of the FE model. Similarly, Figure $7 \mathrm{c}, \mathrm{d}$ shows the corresponding temperatures of key node P3 and P10 with the parameters of the FE model optimized. 


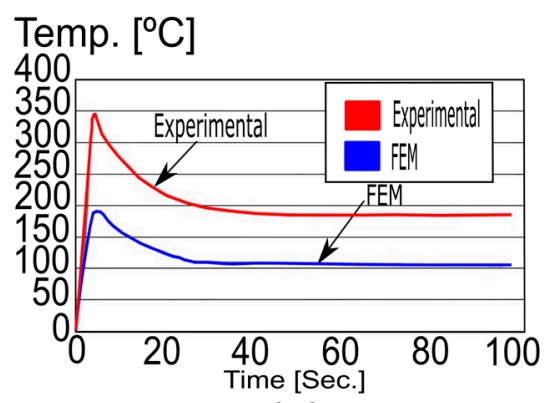

(a)

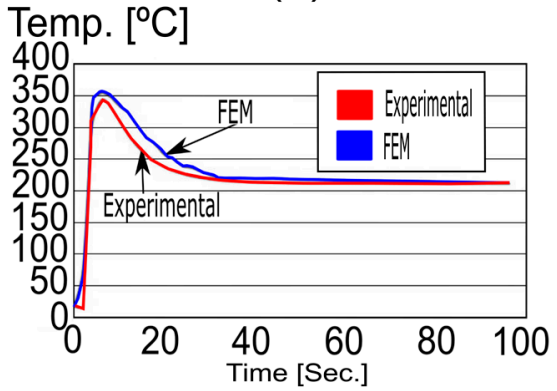

(c)

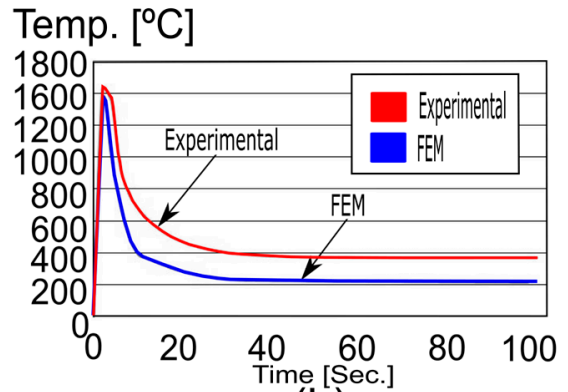

(b)

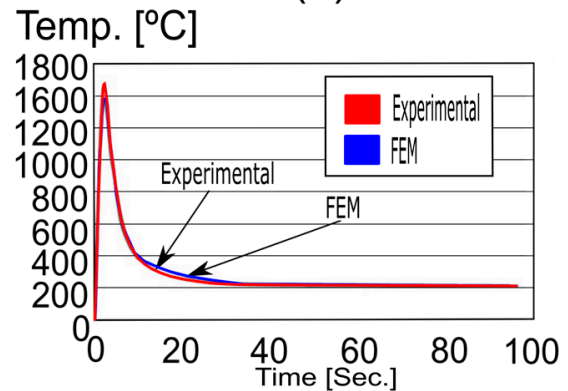

(d)

Figure 7. (a) Temperature of key node P3 without having adjusted the parameters of the FE model; (b) Temperature of key node P10 without having optimized the parameters of the FE model; (c) Temperature of key node P3 with the parameters of the FE model optimized; (d) Temperature of key node P10 with the parameters of the FE model optimized.

Table 2 shows the thirteen input parameters that were obtained for each of the three FE models that were proposed through GA to define the thermal conduction and thermal convection phenomenon. However, it is to be noted that, as the power supplied to the weld joint increases (See Table 1), higher melting point values (melting_point), thermal contacts between the weld bead and both plates for the central zone and the end zone of the bead (contac_P_center and contac_P_end) and thermal contact between plates 1 and 2 with the ground (contact_P_G) generally increased also. For example, the melting_point value varies from 1427 to 1429 , whereas the values for contac_P_center, contac_P_end and contact_P_G vary from 10 to 662, from 19 to 247 , and from 66 to 182, respectively. Furthermore, the values that achieve the objective function increase as the power supplied is increased. This means that the models provide a better fit when the power that is supplied to the welded joint is lower.

Table 2. Adjusted values obtained through genetic algorithms (GA) for the parameters that define each of the thermal conduction and thermal convection phenomenon of the three FE models.

\begin{tabular}{|c|c|c|c|c|c|c|c|}
\hline Specimen & $\begin{array}{l}\text { Melting } \\
\text { Point }\left({ }^{\circ} \mathrm{C}\right)\end{array}$ & $\begin{array}{l}\text { Contact_P_Init } \\
(\mathbf{N} / \mathrm{s} / \mathbf{K})\end{array}$ & $\begin{array}{c}\text { Contact_P_Center } \\
(\mathbf{N} / \mathbf{s} / \mathbf{K})\end{array}$ & $\begin{array}{l}\text { Contact_P_End } \\
(\mathrm{N} / \mathrm{s} / \mathrm{K})\end{array}$ & $\begin{array}{c}\text { Contact_P1_P2 } \\
\text { (N/s/K) }\end{array}$ & $\begin{array}{c}\text { Contact_P_G } \\
(\mathbf{N} / \mathbf{s} / \mathbf{K})\end{array}$ & $\begin{array}{c}\text { Face_Film } \\
(\mathrm{N} / \mathrm{s} / \mathrm{K} / \mathrm{mm})\end{array}$ \\
\hline 01 & 1427 & 17 & 10 & 19 & 193 & 66 & 0.00052 \\
\hline 02 & 1425 & 257 & 65 & 189 & 195 & 176 & 0.00071 \\
\hline Specimen & $\begin{array}{l}\text { Face_Film } 2 \\
(\mathrm{~N} / \mathrm{s} / \mathrm{K} / \mathrm{mm})\end{array}$ & $\begin{array}{l}\text { Face_Film } 3 \\
(\mathrm{~N} / \mathrm{s} / \mathrm{K} / \mathrm{mm})\end{array}$ & $\begin{array}{c}\text { Forward } \\
\text { Length }(\mathrm{mm})\end{array}$ & $\begin{array}{l}\text { Rear Length } \\
(\mathrm{mm})\end{array}$ & Width (mm) & Depth (mm) & $J_{\text {tempj }}$ \\
\hline 03 & 0.0008 & 0.00068 & 1.6 & 5.2 & 23.1 & 5.4 & 6.349 \\
\hline
\end{tabular}

\subsection{Results of the Angular Distortion and Residual Stresses}

Once the parameters that define the thermal conduction and convection were adjusted with the thermal field for each of the FE models (elements with coarse mesh), the following parameters that 
define the Chaboche model were proposed for all FE models with reduced mesh size. These parameters were: Yield stress $=235 \mathrm{MPa}, b=17.7, C=24506 \mathrm{MPa}, \gamma=2462.6, Q_{\mathrm{M}}=191.4 \mathrm{MPa}, Q_{0}=221.9 \mathrm{MPa}$, $\mu=118.3, \eta=0.5$, and $n=4.1$.

Table 3 shows the angular distortions obtained for each of these FE models with reduced mesh size, the angular deformation values obtained experimentally using a coordinate-measuring machine, and as the error for each of the welded specimens. The table indicates that the largest error was with specimen $2(8.4 \%)$, whereas the smallest error was with specimen $1(7.3 \%)$.

Table 3. Values of the angular distortion obtained with the proposed FE models proposed and experimentally by use of a coordinate-measuring machine.

\begin{tabular}{cccc}
\hline Specimen & FEM $\left.^{(}\right)$ & Experimental $\left({ }^{\circ}\right)$ & Error $(\%)$ \\
\hline 1 & 4.98 & 4.64 & 7.3 \\
2 & 5.12 & 4.723 & 8.4 \\
3 & 5.31 & 4.934 & 7.6 \\
\hline
\end{tabular}

Also, Figure 8a shows the values of Von Mises residual stresses that were obtained from the FE model with reduced mesh for the first of the specimens welded after $100 \mathrm{~s}$ of simulation. Also, the figure shows six key points that are situated close to the weld toe and correspond to the positions of the six CEA-06-062UM-120 strain gauge rosettes that were used to determine residual stresses experimentally. These six key points of the FE model provided the values of the longitudinal and transversal stresses $\left(\sigma_{\mathrm{x}}\right.$ and $\left.\sigma_{\mathrm{y}}\right)$ and the values that correspond to the principal stresses $\left(\sigma_{\mathrm{I}}\right.$ and $\left.\sigma_{\mathrm{II}}\right)$ of the welded joint. Similarly, Figure $8 \mathrm{~b}$ shows typical values of the longitudinal and transversal stresses $\left(\sigma_{\mathrm{x}}\right.$ and $\left.\sigma_{\mathrm{y}}\right)$ on the surface of the welded joint for any butt with a single V-groove that appears in the literature $[4,70]$.

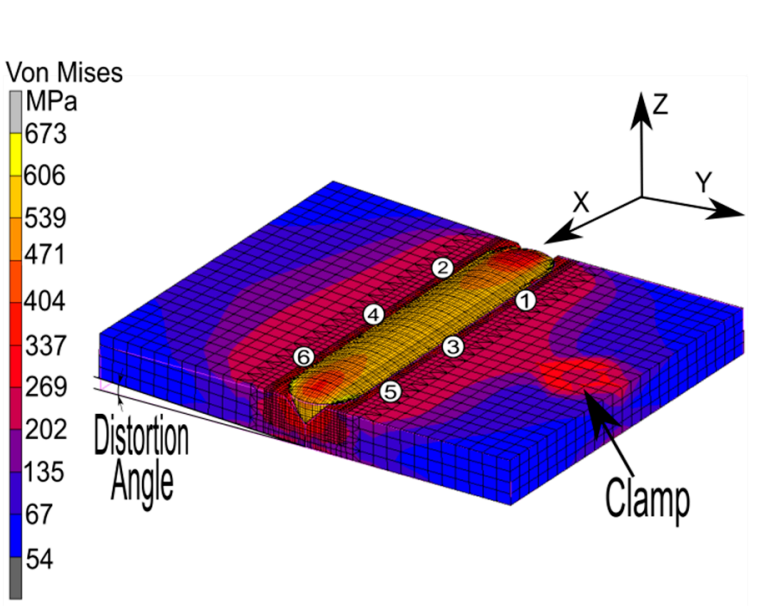

(a)

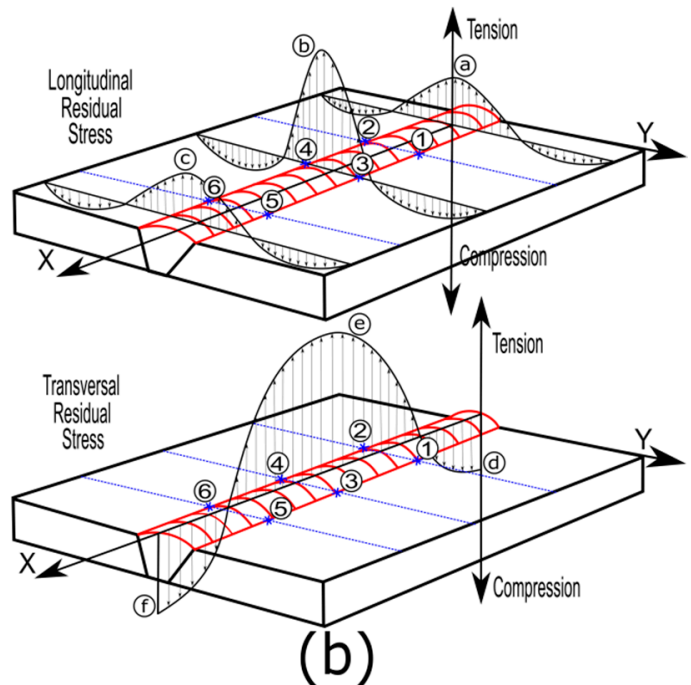

(b)

Figure 8. (a) Von Mises stresses obtained from the FE model of a butt joint with a single V-groove for the first specimen studied; (b) Theoretical distribution of longitudinal and transverse stresses that appear in the literature $[4,70]$ for welding any butt welded joint with single V-groove.

Also, Table 4 shows the values of the longitudinal and transversal stresses $\left(\sigma_{x}\right.$ and $\left.\sigma_{y}\right)$ on the surface and close to the weld toe of the butt joint with a single V-groove for the three proposed FE models.

This table shows that, with increasing the power supplied to the welded joint, the longitudinal and transversal distribution of residual stresses on the surface of the welded joint also increase. This is 
due to increased supply of heat by the GMAW welding torch [71]. Also, Figure 9 shows a comparison of the longitudinal (Figure 9a) and transversal (Figure 9b) residual stresses that were obtained by the three proposed FE models (results of strain gauge rosette 1 shown in Table 4) and the theoretical model proposed in the literature [4,70]. A certain similarity between the sign, the relative values, as well as the general shape of the longitudinal and transverse stresses obtained from the proposed FE models and those values shown in the literature, can be seen. Similar results were obtained for the second and third welded specimens.

Table 4. Values of the longitudinal and transversal stresses $\left(\sigma_{\mathrm{x}}\right.$ and $\left.\sigma_{\mathrm{y}}\right)$ on the surface and close to the weld toe of the butt joint with a single V-groove for the three proposed FE models.

\begin{tabular}{cccccccc}
\hline Sp. & Res. Str. (MPa) & Rosette 1 & Rosette 2 & Rosette 3 & Rosette 4 & Rosette 5 & Rosette 6 \\
\hline \multirow{2}{*}{1} & $\sigma_{\mathrm{x}}$ & 481.9 & 477.2 & 513.1 & 514.9 & 477.4 & 477.5 \\
& $\sigma_{\mathrm{y}}$ & 200.0 & 201.6 & 219.0 & 222.1 & 201.5 & 203.8 \\
\hline \multirow{2}{*}{2} & $\sigma_{\mathrm{x}}$ & 517.0 & 512.1 & 541.0 & 540.7 & 506.2 & 503.5 \\
& $\sigma_{\mathrm{y}}$ & 221.8 & 223.5 & 246.5 & 238.8 & 230.6 & 224.5 \\
\hline \multirow{2}{*}{3} & $\sigma_{\mathrm{x}}$ & 575.9 & 567.9 & 600.9 & 596.8 & 582.5 & 581.2 \\
& $\sigma_{\mathrm{y}}$ & 259.9 & 249.5 & 294.4 & 293.5 & 264.0 & 255.1 \\
\hline
\end{tabular}

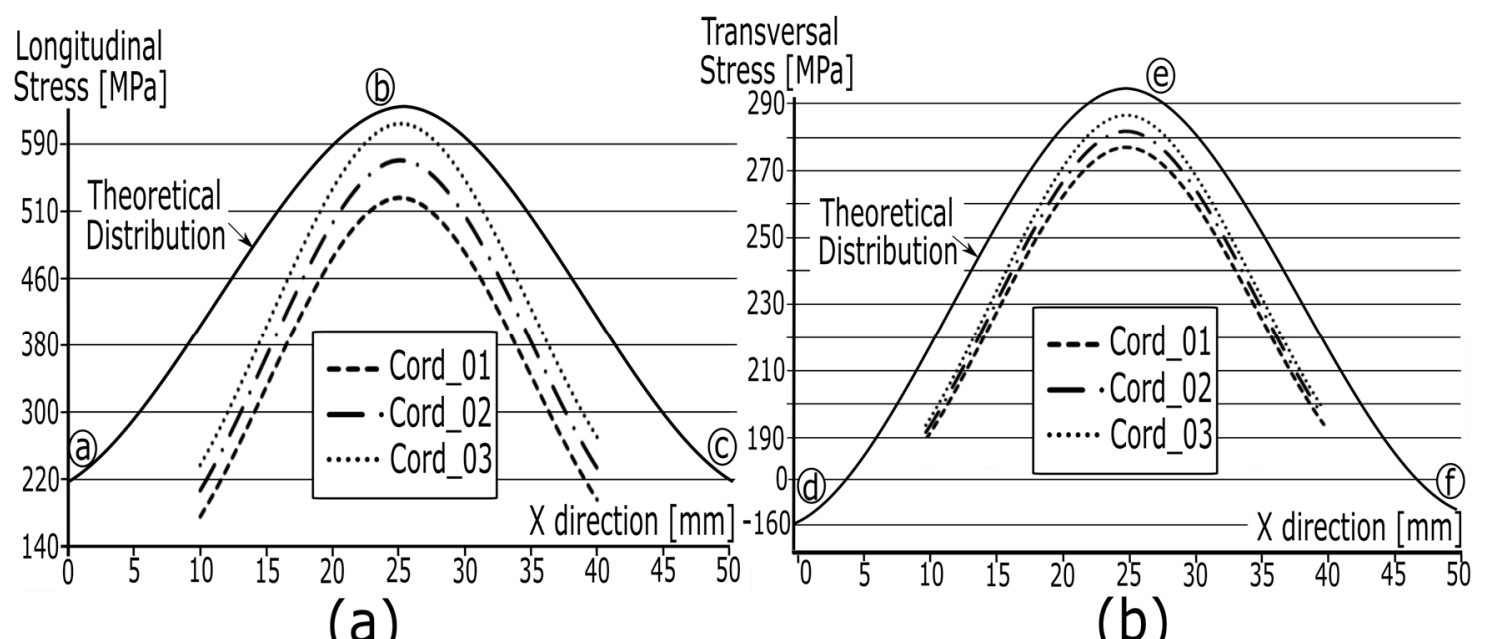

Figure 9. (a) Comparison of the longitudinal (a) and transversal (b) residual stresses ( $\sigma_{x}$ and $\sigma_{y}$ ) obtained by the three proposed FE models, and the theoretical model that is proposed in the literature $[4,70]$.

Tables $5-7$ show the values of the micro strains $\left(\varepsilon_{1}, \varepsilon_{2}\right.$ and $\left.\varepsilon_{3}\right)$, as well as the angle $(\alpha)$ obtained from the six rosettes for each of the standard depths that were studied. In this case, the values of the angle $(\alpha)$ were calculated according to Equation (19), taking the nearer principal axis to the strain gauge no1 as a reference $[39,40]$. It can be seen in these tables that the values of the micro deformations of the specimens that were studied do not differ significantly. However, it can be seen that, as the power supplied for manufacturing the welded joint increases, the value of the micro strain also increases. Furthermore, $\alpha$ remains almost constant for each of the standard depths those were studied. According to $[39,40]$, it can be assumed that the variation of the principal residual stresses for the depths studied is homogeneous and that the experimental results obtained are valid. 
Table 5. Micro strains $\left(\varepsilon_{1}, \varepsilon_{2}\right.$ and $\left.\varepsilon_{3}\right)$ and $\alpha$-angles obtained in the butt joint with single V-groove for the first welded specimen.

\begin{tabular}{cccc}
\hline \multirow{2}{*}{ Depth (mm) } & Rosette 1 & Rosette 2 & Rosette 3 \\
\cline { 2 - 4 } & $\varepsilon_{1} / \varepsilon_{2} / \varepsilon_{3} / \alpha$ & $\varepsilon_{1} / \varepsilon_{2} / \varepsilon_{3} / \alpha$ & $-33 /-8 /-20 /-35.3$ \\
\hline 0.127 & $-31 /-7 /-18 /-34.8$ & $-30 /-7 /-19 /-36.3$ & $-41 /-11 /-25 /-35.0$ \\
0.254 & $-40 /-11 /-24 /-34.5$ & $-39 /-11 /-25 /-35.8$ & $-43 /-14 /-28 /-35.4$ \\
0.508 & $-43 /-14 /-27 /-34.5$ & $-42 /-14 /-28 /-35.8$ & $-47 /-18 /-31 /-34.6$ \\
0.762 & $-46 /-17 /-30 /-34.5$ & $-45 /-18 /-31 /-35.4$ & $-49 /-18 /-32 /-34.6$ \\
1.016 & $-48 /-18 /-32 /-35.0$ & $-48 /-18 /-32 /-35.0$ & $-52 /-19 /-34-34.7$ \\
1.27 & $-50 /-19 /-33 /-34.6$ & $-50 /-19 /-34 /-35.4$ & Rosette 6 \\
\hline \multirow{2}{*}{ Depth (mm) } & Rosette 4 & Rosette 5 & $\varepsilon_{1} / \varepsilon_{2} / \varepsilon_{3} / \alpha$ \\
\hline 0.127 & $\varepsilon_{1} / \varepsilon_{2} / \varepsilon_{3} / \alpha$ & $\varepsilon_{1} / \varepsilon_{2} / \varepsilon_{3} / \alpha$ & $-29 /-7 /-20 /-37.7$ \\
0.254 & $-32 /-8 /-21 /-36.7$ & $-30 /-7 /-19 /-36.3$ & $-38 /-10 /-25 /-26.6$ \\
0.508 & $-40 /-11 /-26 /-36.2$ & $-37 /-10 /-26 /-37.8$ & $-41 /-14 /-29 /-37.0$ \\
0.762 & $-42 /-14 /-29 /-36.6$ & $-40 /-13 /-29 /-37.8$ & $-43 /-16 /-31 /-37.0$ \\
1.016 & $-46 /-19 /-32 /-35.4$ & $-43 /-17 /-32 /-37.4$ & $-46 /-17 /-33 /-36.9$ \\
1.27 & $-49 /-20 /-32 /-33.7$ & $-46 /-17 /-33 /-37.0$ & $-50 /-18 /-34 /-35.8$ \\
\hline
\end{tabular}

Table 6. Micro strains $\left(\varepsilon_{1}, \varepsilon_{2}\right.$ and $\left.\varepsilon_{3}\right)$ and $\alpha$-angles obtained in the butt joint with a single V-groove for the second welded specimen.

\begin{tabular}{|c|c|c|c|}
\hline \multirow{2}{*}{ Depth (mm) } & Rosette 1 & Rosette 2 & Rosette 3 \\
\hline & $\varepsilon_{1} / \varepsilon_{2} / \varepsilon_{3} / \alpha$ & $\varepsilon_{1} / \varepsilon_{2} / \varepsilon_{3} / \alpha$ & $\varepsilon_{1} / \varepsilon_{2} / \varepsilon_{3} / \alpha$ \\
\hline 0.127 & $-33 /-8 /-20 /-35.3$ & $-32 /-8 /-21 /-36.7$ & $-35 /-10 /-22 /-35.3$ \\
\hline 0.254 & $-42 /-13 /-27 /-35.3$ & $-41 /-13 /-27 /-35.8$ & $-43 /-11 /-27-35.8$ \\
\hline 0.508 & $-44 /-15 /-29 /-35.4$ & $-43 /-14 /-28 /-35.4$ & $-45 /-14 /-31-36.8$ \\
\hline 0.762 & $-47 /-17 /-31 /-35.0$ & $-46 /-16 /-30 /-35.0$ & $-47 /-16 /-32 /-36.2$ \\
\hline 1.016 & $-48 /-19 /-33 /-35.4$ & $-48 /-18 /-33 /-35.8$ & $-50 /-18 /-35 /-36.5$ \\
\hline 1.27 & $-50 /-20 /-34 /-35.0$ & $-50 /-20 /-34 /-35.0$ & $-51 /-19 /-36 /-36.5$ \\
\hline \multirow{2}{*}{ Depth (mm) } & Rosette 4 & Rosette 5 & Rosette 6 \\
\hline & $\varepsilon_{1} / \varepsilon_{2} / \varepsilon_{3} / \alpha$ & $\varepsilon_{1} / \varepsilon_{2} / \varepsilon_{3} / \alpha$ & $\varepsilon_{1} / \varepsilon_{2} / \varepsilon_{3} / \alpha$ \\
\hline 0.127 & $-34 /-9 /-22 /-36.2$ & $-32 /-9 /-21 /-36.3$ & $-32 /-8 /-21 /-36.7$ \\
\hline 0.254 & $-43 /-12 /-28 /-36.2$ & $-42 /-13 /-28 /-36.1$ & $-41 /-13 /-28 /-36.6$ \\
\hline 0.508 & $-46 /-15 /-31 /-36.2$ & $-44 /-15 /-29 /-35.4$ & $-43 /-14 /-29 /-36.2$ \\
\hline 0.762 & $-49 /-19 /-33 /-35.0$ & $-45 /-17 /-30 /-34.9$ & $-45 /-16 /-31 /-36.2$ \\
\hline 1.016 & $-50 /-20 /-34 /-35.0$ & $-47 /-19 /-31 /-34.1$ & $-47 /-18 /-33-36.2$ \\
\hline 1.27 & $-52 /-19 /-34 /-34.7$ & $-50 /-21 /-33 /-33.7$ & $-50 /-19 /-34-35.4$ \\
\hline
\end{tabular}

Table 7. Micro strains $\left(\varepsilon_{1}, \varepsilon_{2}\right.$ and $\left.\varepsilon_{3}\right)$ and $\alpha$-angles obtained in the butt joint with a single V-groove for the third welded specimen.

\begin{tabular}{cccc}
\hline \multirow{2}{*}{ Depth (mm) } & Rosette 1 & Rosette 2 & Rosette 3 \\
\cline { 2 - 4 } & $\varepsilon_{1} / \varepsilon_{2} / \varepsilon_{3} / \alpha$ & $\varepsilon_{1} / \varepsilon_{2} / \varepsilon_{3} / \alpha$ & $-39 /-13 /-26 /-35.7$ \\
\hline 0.127 & $-36 /-10 /-24 /-36.6$ & $-35 /-9 /-24 /-37.4$ & $-51 /-17 /-35 /-36.4$ \\
0.254 & $-46 /-16 /-32 /-36.5$ & $-44 /-15 /-31 /-36.9$ & $-54 /-21 /-39 /-36.8$ \\
0.508 & $-48 /-19 /-34 /-36.1$ & $-47 /-17 /-33 /-36.5$ & $-61 /-24 /-43 /-36.0$ \\
0.762 & $-52 /-21 /-38 /-36.8$ & $-51 /-20 /-36 /-36.1$ & $-63 /-26 /-44 /-35.4$ \\
1.016 & $-57 /-24 /-42 /-36.8$ & $-55 /-24 /-43 /-38.2$ & $-61 /-27 /-46 /-37.1$ \\
1.27 & $-61 /-27 /-45 /-36.4$ & $-60 /-25 /-44 /-36.7$ & Rosette 6 \\
\hline \multirow{2}{*}{ Depth (mm) } & Rosette 4 & Rosette 5 & $\varepsilon_{1} / \varepsilon_{2} / \varepsilon_{3} / \alpha$ \\
\hline 0.127 & $\varepsilon_{1} / \varepsilon_{2} / \varepsilon_{3} / \alpha$ & $\varepsilon_{1} / \varepsilon_{2} / \varepsilon_{3} / \alpha$ & $-35 /-9 /-25 /-38.3$ \\
0.254 & $-38 /-13 /-26 /-36.2$ & $-36 /-10 /-25 /-37.4$ & $-45 /-15 /-33 /-37.9$ \\
0.508 & $-50 /-18 /-35 /-36.4$ & $-44 /-16 /-33 /-38.1$ & $-47 /-18 /-34 /-36.9$ \\
0.762 & $-55 /-22 /-39 /-36.1$ & $-46 /-19 /-34 /-37.0$ & $-51 /-20 /-37 /-36.8$ \\
1.016 & $-62 /-25 /-43 /-35.4$ & $-50 /-21 /-37 /-36.9$ & $-56 /-23 /-41 /-36.8$ \\
1.27 & $-64 /-27 /-45 /-35.4$ & $-56 /-22 /-42 /-37.7$ & $-60 /-26 /-44 /-36.4$ \\
\hline
\end{tabular}


With the micro strains $\left(\varepsilon_{1}, \varepsilon_{2}\right.$, and $\left.\varepsilon_{3}\right)$ obtained experimentally and using Equations (13)-(16), the principal stresses $\sigma_{I}$ and $\sigma_{I I}$ can be calculated for the three specimens studied at different standardized depths of the six rosettes. These values of $\sigma_{I}$ and $\sigma_{I I}$ corresponded to the values obtained experimentally from the hole drilling method. However, because the studied normalized depths $(0.127$, $0.254,0.508,0.762,1.016$, and $1.27 \mathrm{~mm}$ ) did not correspond to the coordinates of the nodes of the FE models that were proposed (mesh size $=0.18 \mathrm{~mm}$; See Section 6.2), an interpolation of the principal stresses $\sigma_{\mathrm{I}}$ and $\sigma_{\mathrm{II}}$ that were obtained from the FE models at the normalized depths had to be made in order to obtain the stresses from the FE models. Tables 8-10 show the principal stresses $\left(\sigma_{I}\right.$ and $\left.\sigma_{\text {II }}\right)$ that were obtained from the FE models and also those that were obtained experimentally using strain gauge rosettes. It can be seen in all tables that the maximum values of the principal stresses $\sigma_{I}$ and $\sigma_{\text {II }}$ that were obtained from the FE models and the experiments with the three specimens studied correspond to a depth of $0.127 \mathrm{~mm}$. This corresponds practically to the stresses obtained on the surface of the welded joint (according to the literature [4,70]). Also, the tables show the MAE of the different rosettes that were studied. They were calculated from the results obtained experimentally and those obtained from the proposed FE models (see Equation (22)). One can see that, for the first welded specimen, the maximum MAE corresponds to the rosette no4 (14.27 for $\sigma_{\mathrm{I}}$ and 5.85 for $\left.\sigma_{\mathrm{II}}\right)$, whereas the minimum MAE corresponds to the rosette no5 (11.93 for $\sigma_{\mathrm{I}}$ and 4.44 for $\left.\sigma_{\mathrm{II}}\right)$. Similarly, it can be noted that, for the second welded specimen, the maximum MAE corresponds to the rosette no4 (15.35 for $\sigma_{\mathrm{I}}$ and 5.5 for $\left.\sigma_{\mathrm{II}}\right)$, whereas the minimum MAE corresponds to the rosette no6 (14.17 for $\sigma_{\mathrm{I}}$ and 3.90 for $\left.\sigma_{\mathrm{II}}\right)$. Finally, for the second welded specimen, the maximum MAE corresponds to the rosette no1 (15.80 for $\sigma_{\mathrm{I}}$ and 6.56 for $\sigma_{\mathrm{II}}$ ), whereas the minimum MAE corresponds to the rosette no3 (13.38 for $\sigma_{\mathrm{I}}$ and 5.20 for $\left.\sigma_{\text {II }}\right)$.

Because the values of the MAEs for the specimens that were studied are reduced (approximately 15), we can assume that the parameters that were selected to define the Chaboche of the FE models (Yield stress $=235 \mathrm{MPa}, b=17.7, C=24506 \mathrm{MPa}, \gamma=2462.6, Q_{\mathrm{M}}=191.4 \mathrm{MPa}, Q_{0}=221.9 \mathrm{MPa}$, $\mu=118.3, \eta=0.5$, and $n=4.1$ ) may be used to reproduce accurately the behavior of the butt joints with a single $\mathrm{V}$-groove.

Table 8. Values of the principal stresses $\left(\sigma_{\mathrm{I}}\right.$ and $\left.\sigma_{\mathrm{II}}\right)$ at different depths in the butt joint with a single $\mathrm{V}$-groove for the first welded specimen.

\begin{tabular}{cccccccc}
\hline \multirow{2}{*}{$\begin{array}{c}\text { Principal } \\
\text { Stresses }\end{array}$} & $\begin{array}{c}\text { Depth } \\
(\mathbf{m m})\end{array}$ & Rosette 1 & Rosette 2 & Rosette 3 & Rosette 4 & Rosette 5 & Rosette 6 \\
\cline { 3 - 8 } & 0.127 & $467.9 / 461.9$ & $465.6 / 460.4$ & $501.6 / 496.3$ & $499.4 / 494.1$ & $465.5 / 460.4$ & $463.6 / 458.4$ \\
& 0.254 & $226.4 / 252.1$ & $225.0 / 250.4$ & $234.4 / 260.0$ & $233.5 / 259.0$ & $222.9 / 247.7$ & $223.4 / 248.5$ \\
& 0.508 & $144.1 / 128.8$ & $143.3 / 135.5$ & $146.3 / 137.9$ & $145.5 / 137.4$ & $141.4 / 134.1$ & $142.2 / 135.1$ \\
$\sigma_{\text {I }}(\mathrm{MPa})$ & 0.762 & $108.4 / 92.7$ & $108.1 / 83.0$ & $110.1 / 85.8$ & $109.1 / 84.6$ & $106.9 / 82.2$ & $107.4 / 81.9$ \\
& 1.016 & $79.7 / 76.8$ & $79.7 / 75.6$ & $81.6 / 76.8$ & $80.4 / 75.4$ & $79.4 / 74.9$ & $79.5 / 74.9$ \\
& 1.27 & $52.9 / 68.3$ & $53.4 / 70.3$ & $55.3 / 72.4$ & $53.9 / 71.2$ & $53.9 / 70.9$ & $53.6 / 70.9$ \\
\hline $\mathrm{MAE}$ & & 13.86 & 14.09 & 14.23 & 14.27 & 11.93 & 14.13 \\
\hline & 0.127 & $194.7 / 197.0$ & $196.9 / 199.1$ & $214.5 / 217.0$ & $216.5 / 219.2$ & $196.7 / 199.1$ & $198.4 / 201.0$ \\
& 0.254 & $120.7 / 114.2$ & $122.0 / 115.2$ & $126.1 / 117.1$ & $127.7 / 118.0$ & $120.0 / 112.2$ & $120.3 / 111.4$ \\
& 0.508 & $68.6 / 66.2$ & $69.3 / 72.4$ & $69.1 / 73.0$ & $70.1 / 73.4$ & $67.4 / 70.8$ & $67.3 / 72.8$ \\
$\sigma_{\text {II }}(\mathrm{MPa})$ & 0.762 & $47.9 / 49.8$ & $48.4 / 43.8$ & $47.6 / 44.3$ & $48.3 / 45.5$ & $46.9 / 42.9$ & $46.7 / 41.5$ \\
& 1.016 & $36.8 / 42.2$ & $37.2 / 40.8$ & $36.3 / 41.1$ & $36.9 / 42.4$ & $35.9 / 40.1$ & $35.8 / 40.1$ \\
& 1.27 & $29.9 / 38.6$ & $30.2 / 39.1$ & $29.3 / 39.6$ & $29.8 / 40.8$ & $29.1 / 38.5$ & $29.0 / 38.5$ \\
\hline MAE & & 5.00 & 4.87 & 5.63 & 5.85 & 4.44 & 6.01 \\
\hline
\end{tabular}


Table 9. Values of the principal stresses $\left(\sigma_{I}\right.$ and $\left.\sigma_{\text {II }}\right)$ at different depths in the butt joint with a single V-groove for the second welded specimen.

\begin{tabular}{cccccccc}
\hline \multirow{2}{*}{$\begin{array}{c}\text { Principal } \\
\text { Stresses }\end{array}$} & $\begin{array}{c}\text { Depth } \\
(\mathbf{m m})\end{array}$ & Rosette 1 & Rosette 2 & Rosette 3 & Rosette 4 & Rosette 5 & Rosette 6 \\
\cline { 3 - 8 } & 0.127 & $501.9 / 496.3$ & $499.6 / 494.1$ & $528.8 / 523.3$ & $524.4 / 518.8$ & $493.6 / 487.3$ & $488.8 / 494.1$ \\
& 0.254 & $239.5 / 266.6$ & $235.5 / 261.8$ & $250.1 / 277.2$ & $250.9 / 278.1$ & $253.4 / 270.4$ & $281.4 / 265.7$ \\
& 0.508 & $150.3 / 140.9$ & $147.1 / 137.9$ & $156.3 / 148.5$ & $157.5 / 149.5$ & $151.2 / 140.8$ & $130.5 / 139.8$ \\
\multirow{2}{*}{$\sigma_{\text {I }}(\mathrm{MPa})$} & 0.762 & $111.8 / 86.8$ & $109.9 / 85.0$ & $116.5 / 88.7$ & $116.9 / 90.0$ & $111.2 / 82.7$ & $56.2 / 84.7$ \\
& 1.016 & $80.7 / 75.9$ & $80.3 / 76.6$ & $84.7 / 80.9$ & $84.1 / 78.6$ & $78.5 / 72.8$ & $69.6 / 75.4$ \\
& 1.27 & $51.9 / 69.7$ & $52.9 / 69.7$ & $55.1 / 73.0$ & $53.5 / 72.5$ & $47.9 / 68.2$ & $90.7 / 70.3$ \\
\hline $\mathrm{MAE}$ & & 14.97 & 14.39 & 15.00 & 15.35 & 14.71 & 14.17 \\
\hline & 0.127 & $216.0 / 217.0$ & $218.3 / 219.2$ & $241.4 / 243.9$ & $232.7 / 234.9$ & $225.1 / 226.0$ & $218.6 / 219.2$ \\
& 0.254 & $130.9 / 127.6$ & $129.5 / 126.7$ & $127.1 / 122.7$ & $135.9 / 127.5$ & $132.7 / 129.5$ & $130.4 / 128.5$ \\
& 0.508 & $73.2 / 76.0$ & $71.4 / 73.0$ & $72.2 / 77.3$ & $74.2 / 79.2$ & $72.84 / 76.0$ & $72.2 / 74.0$ \\
$\sigma_{\text {II }}(\mathrm{MPa})$ & 0.762 & $50.8 / 43.7$ & $49.3 / 41.8$ & $45.1 / 43.1$ & $51.0 / 46.8$ & $50.2 / 42.4$ & $49.9 / 42.1$ \\
& 1.016 & $38.9 / 42.0$ & $37.6 / 41.3$ & $36.3 / 42.8$ & $38.8 / 43.8$ & $38.2 / 40.7$ & $38.1 / 41.1$ \\
& 1.27 & $31.5 / 39.7$ & $30.4 / 39.7$ & $29.2 / 40.3$ & $31.4 / 39.6$ & $30.9 / 39.8$ & $30.9 / 39.1$ \\
\hline MAE & & 4.30 & 4.31 & 5.27 & 5.50 & 4.40 & 3.90 \\
\hline
\end{tabular}

Table 10. Values of the principal stresses $\left(\sigma_{\mathrm{I}}\right.$ and $\left.\sigma_{\mathrm{II}}\right)$ at different depths in the butt joint with a single V-groove for the third welded specimen.

\begin{tabular}{cccccccc}
\hline \multirow{2}{*}{$\begin{array}{c}\text { Principal } \\
\text { Stresses }\end{array}$} & $\begin{array}{c}\text { Depth } \\
(\mathbf{m m})\end{array}$ & Rosette 1 & Rosette 2 & Rosette 3 & Rosette 4 & Rosette 5 & Rosette 6 \\
\cline { 3 - 8 } & 0.127 & $559.1 / 552.5$ & $554.0 / 548.2$ & $587.4 / 583.8$ & $578.9 / 572.6$ & $568.0 / 561.7$ & $564.3 / 557.5$ \\
& 0.254 & $278.68 / 296.2$ & $257.6 / 285.8$ & $301.0 / 328.7$ & $302.3 / 321.0$ & $272.5 / 290.7$ & $291.5 / 298.3$ \\
& 0.508 & $166.9 / 154.7$ & $161.7 / 153.1$ & $188.3 / 176.0$ & $188.7 / 177.0$ & $161.4 / 149.9$ & $166.6 / 153.7$ \\
\multirow{2}{*}{$\sigma_{\mathrm{I}}(\mathrm{MPa})$} & 0.762 & $127.1 / 98.2$ & $123.7 / 95.4$ & $136.5 / 113.9$ & $142.7 / 114.5$ & $123.4 / 94.2$ & $126.2 / 96.5$ \\
& 1.016 & $95.8 / 91.9$ & $94.3 / 90.5$ & $103.7 / 99.5$ & $104.9 / 101.0$ & $94.2 / 92.1$ & $94.3 / 90.4$ \\
& 1.27 & $66.9 / 86.5$ & $67.3 / 85.8$ & $67.0 / 87.3$ & $69.5 / 88.6$ & $67.7 / 85.9$ & $65.0 / 85.1$ \\
\hline $\mathrm{MAE}$ & & 15.80 & 15.54 & 15.10 & 14.66 & 14.26 & 13.38 \\
\hline & 0.127 & $253.1 / 255.1$ & $243.7 / 245.9$ & $288.3 / 291.0$ & $286.1 / 288.8$ & $257.7 / 259.3$ & $248.4 / 250.0$ \\
& 0.254 & $155.1 / 149.5$ & $148.9 / 142.8$ & $169.6 / 162.6$ & $166.3 / 164.6$ & $153.6 / 149.29$ & $150.5 / 147.3$ \\
& 0.508 & $86.1 / 88.9$ & $83.8 / 84.6$ & $95.2 / 100.3$ & $97.3 / 102.2$ & $85.8 / 87.74$ & $85.6 / 86.9$ \\
$\sigma_{\text {II }}(\mathrm{MPa})$ & 0.762 & $60.8 / 52.0$ & $58.3 / 49.8$ & $62.4 / 59.6$ & $67.6 / 60.7$ & $56.4 / 50.97$ & $56.9 / 50.3$ \\
& 1.016 & $45.9 / 52.3$ & $44.7 / 52.3$ & $50.3 / 56.3$ & $51.8 / 57.7$ & $45.4 / 50.64$ & $45.6 / 50.8$ \\
& 1.27 & $37.8 / 51.7$ & $36.2 / 49.7$ & $49.3 / 52.0$ & $41.97 / 53.3$ & $36.7 / 49.55$ & $37.0 / 50.3$ \\
\hline MAE & & 6.56 & 6.44 & 4.36 & 5.60 & 5.22 & 5.20 \\
\hline
\end{tabular}

\section{Conclusions}

This paper applies plastic-strain-range memorization based on time-independent cyclic plasticity theory for butt joint with single V-groove Finite Element (FE) models that were manufactured by GMAW. The proposed theory combines both isotropic hardening and the nonlinear kinematic hardening rule (Chaboche model) to reproduce the behavior of cyclic plasticity and, thus, to obtain the residual stresses in welded joint FE models. As a practical example, the theory is validated by three welded joint specimens that were manufactured with different input parameters of speed, voltage and current $(6 \mathrm{~mm} / \mathrm{s}, 26$ volts and $140 \mathrm{amps} ; 6 \mathrm{~mm} / \mathrm{s}, 28$ volts and $210 \mathrm{amps} ; 6 \mathrm{~mm} / \mathrm{s}, 35$ volts and 260 amps). The first step was to generate three butt joint with a single V-groove FE models according to the studied parameters that presented differing cord geometry (height and width) and heat flux. The three proposed FE models respect scrupulously the dimensions of height and width of the specimens that were welded, and were used to determine the thermal field that was created 
during the welding process. In this case, a total of thirteen different parameters (four for the weld flux, six for the thermal conduction phenomena, and three for the thermal convection) were used to define the three FE models. Once the FE models were generated, their thirteen different parameters were adjusted by evolutionary optimization techniques that are based on Genetic Algorithms (GA). For this, the experimental data obtained during the manufacturing process of the three specimens with a thermographic camera were used for a reference. Subsequently, three new FE models with a finer mesh size than that of the previous three FE thermal models were used to solve the strain, angular distortion, and residual stress fields. These new FE models with a finer mesh size were used as boundary conditions for the thirteen parameters that had been adjusted previously and formulated with rate-independent plasticity behavior considering both the isotropic hardening and the nonlinear kinematic hardening rule (Chaboche model). The following Chaboche parameters were adopted for the three FE models: Yield stress $=235 \mathrm{MPa}, b=17.7, C=24,506 \mathrm{MPa}, \gamma=2462.6, Q_{\mathrm{M}}=191.4 \mathrm{MPa}$, $Q_{0}=221.9 \mathrm{MPa}, \mu=118.3, \eta=0.5$, and $n=4.1$. An agreement between the residual stresses that were obtained by the FE model proposed and those obtained experimentally by the hole drilling method at different depths demonstrates that the proposed theory can be valid for modelling the residual stresses in welded joints when cyclic plasticity is considered over the range of speed, voltage, and current studied.

Acknowledgments: The authors wish to thanks the University of La Rioja for its support through Project ADER 2014-I-IDD-00162.

Author Contributions: Experimental work: Ruben Lostado Lorza, María Ángeles Martínez Calvo and Pedro María Villanueva Roldán. Development of the FE models: Ruben Lostado Lorza, Marina Bobadilla Corral. Results analysis and manuscript preparation: all authors.

Conflicts of Interest: The authors declare no conflict of interest.

\section{References}

1. Radaj, D. Heat Effects of Welding: Temperature Field, Residual Stress, Distortion, 1st ed.; Springer: Heidelberg/Berlin, Germany, 1992.

2. Radaj, D. Welding Residual Stresses and Distortion: Calculation and Measurement, 1st ed.; DVS-Verlag: Dusseldorf, Germany, 2003.

3. Macherauch, E.; Kloos, K.H. Origin, measurements and evaluation of residual stresses. In Residual Stress in Science and Technology, 1st ed.; DGM Verlag: Oberursel, Germany, 1987.

4. Totten, G.E.; Howes, M.; Inoue, T. Handbook of Residual Stress and Deformation of Steel, 1st ed.; ASM International: Kinsman Road, OH, USA, 2002.

5. Zambon, A.; Ferro, P.; Bonollo, F. Microstructural, compositional and residual stress evaluation of $\mathrm{CO}_{2}$ laser welded superaustenitic AISI 904L stainless steel. Mater. Sci. Eng. A Struct. 2006, 424, 117-127. [CrossRef]

6. Thibault, D.; Bocher, P.; Thomas, M.; Gharghouri, M.; Côté, M. Residual stress characterization in low transformation temperature $13 \% \mathrm{Cr}-4 \% \mathrm{Ni}$ stainless steel weld by neutron diffraction and the contour method. Mater. Sci. Eng. A Struct. 2010, 527, 6205-6210. [CrossRef]

7. Paradowska, A.; Price, J.W.H.; Ibrahim, R.; Finlayson, T. A neutron diffraction study of residual stress due to welding. J. Mater. Process. Technol. 2005, 164-165, 1099-1105. [CrossRef]

8. Olabi, A.G.; Hashmi, M.S.J. Effects of the stress-relief conditions on a martensite stainless-steel welded component. J. Mater. Process Technol. 1998, 77, 216-225. [CrossRef]

9. Lostado, R.; Escribano, R.; Martínez, M.Á.; Múgica, R. Improvement in the Design of Welded Joints of EN 235JR Low Carbon Steel by Multiple Response Surface Methodology. Metals 2016, 6, 205. [CrossRef]

10. Berge, S. On the effect of plate thickness in fatigue of welds. Eng. Fract. Mech. 1985, 21, 423-435. [CrossRef]

11. Ferreira, J.M.; Branco, C.M. Influence of the radius of curvature at the weld toe in the fatigue strength of fillet welded joints. Int. J. Fatigue 1989, 11, 29-36.

12. Teng, T.L.; Fung, C.P.; Chang, P.H. Effect of weld geometry and residual stresses on fatigue in butt-welded joints. Int. J. Press. Vessels Pip. 2002, 79, 467-482. [CrossRef]

13. Citarella, R.; Carlone, P.; Sepe, R.; Lepore, M. DBEM crack propagation in friction stir welded aluminum joints. Adv. Eng. Softw. 2016, 101, 50-59. [CrossRef] 
14. Citarella, R.; Carlone, P.; Lepore, M.; Sepe, R. Hybrid technique to assess the fatigue performance of multiple cracked FSW joints. Eng. Fract. Mech. 2016, 162, 38-50. [CrossRef]

15. Carlone, P.; Citarella, R.; Sonne, M.R.; Hattel, J.H. Multiple crack growth prediction in AA2024-T3 friction stir welded joints, including manufacturing effects. Int. J. Fatigue 2016, 90, 69-77. [CrossRef]

16. Lostado, R.; Fernandez, R.; Mac Donald, B.J.; Villanueva, P.M. Combining soft computing techniques and the finite element method to design and optimize complex welded products. Integr. Comput.-Aided Eng. 2015, 22, 153-170.

17. Chaboche, J.L. Time-independent constitutive theories for cyclic plasticity. Int. J. Plast. 1986, 2, 149-188. [CrossRef]

18. Lostado, R.; Martínez-de-Pisón, F.J.; Fernández, R.; Fernández, J. Using genetic algorithms to optimize the material behaviour model in finite element models of processes with cyclic loads. J. Strain Anal. Eng. 2011, 46, 143-159. [CrossRef]

19. Mandal, N.K.; Dhanasekar, M. Sub-modelling for the ratchetting failure of insulated rail joints. Int. J. Mech. Sci. 2013, 75, 110-122. [CrossRef]

20. Chatti, S.; Chtioui, N. Sheet metal forming simulation using finite elastoplasticity with mixed isotropic/kinematic hardening. Eur. J. Comput. Mech. 2011, 20, 427-453. [CrossRef]

21. Pilipenko, A. Computer Simulation of Residual Stress and Distortion of Thick Plates in Multielectrode Submerged Arc Welding: Their Mitigation Techniques. Ph.D. Thesis, Department of Machine Design and Materials Technology Norwegian University of Science and Technology Trondheim, Trondheim, Norway, 2001.

22. Goldak, J.A.; Akhlaghi, M. Computational Welding Mechanics, 1st ed.; Springer: New York, NY, USA, 2006.

23. Armstrong, P.J.; Frederick, C.O. A Mathematical Representation of the Multiaxial Bauschinger Effect; Central Electricity Generating Board and Berkeley Nuclear Laboratories, Research \& Development Department: Berkely, UK, 1966.

24. Petersson, N.; Popov, E.P. Constitutive relations for generalized loadings. J. Eng. Mech. Div. 1977, 103, 611-627.

25. Krieg, R.D. A practical two surface plasticity theory. Acta Mech. 1975, 42, 641-647. [CrossRef]

26. Dafalias, Y.F.; Popov, E.P. A model of nonlinearly hardening material for complex loading. Acta Mech. 1975, 21, 173-192. [CrossRef]

27. Chaboche, J.L.; Dang Van, K.; Cordier, G.; Boley, B.A. Modelization of the Strain Memory Effect on the Cyclic Hardening of 316 Stainless Steel; North-Holland Publishing Co.: Amsterdam, The Netherlands, 1979.

28. Ohno, N. A constitutive model of cyclic plasticity with a non-hardening strain region. J. Appl. Mech. 1982, 49, 721-727. [CrossRef]

29. Chaboche, J.L. On some modifications of kinematic hardening to improve the description of ratcheting effects. Int. J. Plast. 1991, 7, 661-678. [CrossRef]

30. Dafalias, Y.F.; Kourousis, K.I.; Saridis, G.J. Multiplicative AF kinematic hardening in plasticity. Int. J. Solids Struct. 2008, 45, 2861-2880. [CrossRef]

31. Minnick, H.M. Gas Metal Arc Welding Handbook Textbook, 1st ed.; Goodheart-Willcox: Tinley Park, IL, USA, 2007.

32. Murray, P.E. Selecting parameters for GMAW using dimensional analysis. Weld. J. 2002, 81, 125-131.

33. Ozcelik, S.; Moore, K. Modeling, Sensing and Control of Gas Metal Arc Welding, 1st ed.; Elsevier Science Ltd.: Oxford, UK, 2003.

34. Grong, O. Metallurgical Modelling of Welding. Institute of Materials, 1st ed.; Carlton House Terrace: London, UK, 1997.

35. Liang, G.; Yuan, S. Study on the temperature measurement of AZ31B magnesium alloy in gas tungsten arc welding. Mater. Lett. 2008, 62, 2282-2284. [CrossRef]

36. Bzymek, A.; Czuprýnski, A.; Fidali, M.; Jamrozik, W.; Timofiejczuk, A. Analysis of images recorded during welding processes. In Proceedings of the 9th International Conference on Quantitative InfraRed Thermography, Krakow, Poland, 2-5 July 2018.

37. Tonković, Z.; Perić, M.; Surjak, M.; Garašić, I.; Boras, I.; Rodić, A.; Švaić, S. Numerical and experimental modeling of a T-joint fillet welding process. In Proceedings of the 11th International Conference on Quantitative InfraRed Thermography, Naples, Italy, 11-14 June 2012. 
38. Olabi, A.G.; Lostado, R.; Benyounis, K.Y. Review of Microstructures, Mechanical Properties, and Residual Stresses of Ferritic and Martensitic Stainless-Steel Welded. In Comprehensive Materials Processing; Welding and Bonding Technologies, Elsevier: Oxford, UK, 2014.

39. ASTM E837-13a, Standard Test Method for Determining Residual Stresses by the Hole-Drilling Strain-Gage Method. Available online: https://www.astm.org/Standards/E837.htm (accessed on 20 December 2016).

40. Vishay Precision Group. Measurement of Residual Stresses by the Hole-Drilling Strain Gage Method. Technical Note TN-503. 2010. Available online: http:/ / www.vishaypg.com/docs/11053/tn503.pdf (accessed on 20 December 2016).

41. ASTM E407-07 Standard Practice for Microetching Metals and Alloys. Available online: https://zh.scribd. com/document/259609551/ASTM-E407--07-StandardPractice-for-Microetching-Metals-and-Alloys (accessed on 20 December 2016).

42. Schajer, G.S. Application of finite element calculations to residual stress measurements. ASME J. Eng. Mater. Technol. 1981, 103, 157-163. [CrossRef]

43. ASTM E92-16, Standard Test Methods for Vickers Hardness and Knoop Hardness of Metallic Materials. Available online: http:/ / www.astm.org/Standards/E92 (accessed on 20 December 2016).

44. Barsoum, Z. Residual stress prediction and relaxation in welded tubular joint. Weld. World 2007, 51, 23-30. [CrossRef]

45. Friedman, E. Thermomechanical analysis of the welding process using the finite element method. J. Press. Vessel-Technol. ASME 1975, 97, 206-213. [CrossRef]

46. Muraki, T.; Bryan, J.; Masubuchi, K. Analysis of thermal stresses and metal movement during welding. J. Eng. Mater.-Technol. ASME 1975, 96, 81-84. [CrossRef]

47. Karlsson, C.T. Finite element analysis of temperatures and stresses in a single-pass butt-welded pipe-Influence of mesh density and material modelling. Eng. Comput. 1989, 6, 133-141. [CrossRef]

48. Karlsson, R.I.; Josefson, B.L. Three-dimensional finite element analysis of temperatures and stresses in a single-pass butt-welded pipe. J. Press. Vessel-Technol. ASME 1990, 112, 76-84. [CrossRef]

49. Pardo, E.; Weckman, D.C. Prediction of weld pool and reinforcement dimensions of GMA welds using a finite-element model. Metall. Trans. B 1989, 20, 937-947. [CrossRef]

50. Aarbogh, H.M.; Hamide, M.; Fjaer, H.G.; Mo, A.; Bellet, M. Experimental validation of finite element codes for welding deformations. J. Mater. Process. Technol. 2010, 210, 1681-1689. [CrossRef]

51. Goldak, J.; Chakravarti, A.; Bibby, M. A new finite element model for welding heat sources. Metall. Trans. $B$ 1984, 15, 299-305. [CrossRef]

52. Attarha, M.J.; Sattari-Far, I. Study on welding temperature distribution in thin welded plates through experimental measurements and finite element simulation. J. Mater. Process. Technol. 2011, 211, 688-694. [CrossRef]

53. Bachorski, A.; Painter, M.J.; Smailes, A.J.; Wahab, M.A. Finite-element prediction of distortion during gas metal arc welding using the shrinkage volume approach. J. Mater. Process. Technol. 1999, 92, 405-409. [CrossRef]

54. Zhang, H.; Zhang, G.; Cai, C.; Gao, H.; Wu, L. Fundamental studies on in process controlling angular distortion in asymmetrical double-sided double arc welding. J. Mater. Process. Technol. 2008, 205, $214-223$. [CrossRef]

55. Josefson, B.L. Prediction of residual stresses and distortions in welded structures. J. Offshore Mech. Arct. 1993, 115, 52-57. [CrossRef]

56. Murthy, Y.V.; Rao, G.V.; Iyer, P.K. Numerical simulation of welding and quenching processes using transient thermal and thermo-elastic-plastic formulations. Comput. Struct. 1996, 60, 131-154. [CrossRef]

57. Brickstad, B.; Josefson, B.L. A parametric study of residual stresses in multi-pass butt-welded stainless steel pipes. Int. J. Press. Vessels Pip. 1998, 75, 11-25. [CrossRef]

58. Wen, S.W.; Farrugia, D.C. Finite element modelling of residual stress in pipe welds. Strain 2001, 37, 15-18. [CrossRef]

59. Deng, D.; Murakawa, H. Numerical simulation of temperature field and residual stress in multi-pass welds in stainless steel pipe and comparison with experimental measurements. Comput. Mater. Sci. 2006, 37, 269-277. [CrossRef]

60. Armentani, E.; Esposito, R.; Sepe, R. The influence of thermal properties and preheating on residual stresses in welding. Int. J. Comput. Mater. Sci. Surf. Eng. 2007, 1, 146-162. [CrossRef] 
61. Sepe, R.; Armentani, E.; Lamanna, G.; Caputo, F. Evaluation by FEM of the influence of the preheating and postheating treatments on residual stresses in welding. Key Eng. Mater. 2015, 627, 93-96. [CrossRef]

62. MARC User Guide, Version 2010; MSC Software Corporation: Santa Ana, CA, USA, 2010.

63. Bag, S.; De, A. Development of a three-dimensional heat transfer model for the gas tungsten arc welding process using the finite element method coupled with a genetic algorithm based identification of uncertain input parameters. Metall. Mater. Trans. A 2008, 39, 2698-2710. [CrossRef]

64. Lee, J.; Um, K. A comparison in a back-bead pre-diction of gas metal arc welding using multiple regression analysis and artificial neural network. Opt. Laser Eng. 2000, 4, 149-158. [CrossRef]

65. Lindgren, L.E. Computational Welding Mechanics: Thermomechanical and Microstructural Simulations, 1st ed.; Woodhead Publishing: Cambridge, UK, 2007.

66. Friedman, E. Numerical simulation of the gas tungsten-arc welding process. In Proceedings of the Numerical Modeling of Manufacturing Processes, ASME Winter Annual Meeting, Atlanta, GA, USA, 27 November-2 December 1977.

67. Hibbitt, H.D.; Marcal, P.V. A numerical, thermo-mechanical model for the welding and subsequent loading of a fabricated structure. Comput. Struct. 1973, 3, 1145-1174. [CrossRef]

68. Benzley, S.E.; Perry, E.; Merkley, K.; Clark, B.; Sjaardama, G. A comparison of all hexagonal and all tetrahedral finite element meshes for elastic and elasto-plastic analysis. In Proceedings of the 4th International Meshing Roundtable, Sandia National Laboratories, Albuquerque, NM, USA, 16-17 October 1995.

69. Cifuentes, A.O.; Kalbag, A. A performance study of tetrahedral and hexahedral elements in 3-D finite element structural analysis. Finite Elem. Anal. Des. 1992, 12, 313-318. [CrossRef]

70. Da Nóbrega, J.A.; Diniz, D.D.; Silva, A.A.; Maciel, T.M.; de Albuquerque, V.H.C.; Tavares, J.M.R. Numerical evaluation of temperature field and residual stresses in an API 5L X80 steel welded joint using the finite element method. Metals 2016, 6, 28. [CrossRef]

71. Apostol, G.; Solomon, G.; Iordchescu, D. Input parameters influence on the residual stress and distortions at laser welding using finite element analysis. Ser. D Mech. Eng. 2012, 74, 153-164.

(C) 2017 by the authors. Licensee MDPI, Basel, Switzerland. This article is an open access article distributed under the terms and conditions of the Creative Commons Attribution (CC BY) license (http:/ / creativecommons.org/licenses/by/4.0/). 